\title{
Non Additive Robust Ordinal Regression for urban and territorial planning: an application for siting an urban waste landfill
}

\author{
Silvia Angilella ${ }^{1}$, Marta Bottero ${ }^{2, 凶}$, Salvatore Corrente $^{3}$, Valentina Ferretti $^{4}$, Salvatore Greco ${ }^{5}$, \\ Isabella M. Lami ${ }^{6}$
}

1 Department of Economics and Business, University of Catania, Corso Italia 55, 95129, Catania, Italy. Email: angisil@unict.it

2 Department of Regional and Urban Studies and Planning (DIST), Politecnico of Torino, Viale Mattioli 39, 10125

Turin, Italy. Email: marta.bottero@polito.it

3 Department of Economics and Business, University of Catania, Corso Italia 55, 95129, Catania, Italy. Email:

salvatore.corrente@unict.it

4 Department of Regional and Urban Studies and Planning (DIST), Politecnico of Torino, Viale Mattioli 39, 10125

Turin, Italy. Email: valentina.ferretti@polito.it

5 Department of Economics and Business, University of Catania, Corso Italia 55, 95129, Catania, Italy.

Portsmouth Business School, Operations \& Systems Management, University of Portsmouth, Portsmouth PO1 3DE,

United Kingdom. Email: salgreco@unict.it

6 Department of Regional and Urban Studies and Planning (DIST), Politecnico of Torino, Viale Mattioli 39, 10125

Turin, Italy. Email: isabella.lami@ polito.it.

\section{Abstract}

In this paper we deal with an urban and territorial planning problem by applying the Non Additive Robust Ordinal Regression (NAROR). NAROR is a recent extension of the Robust Ordinal Regression (ROR) family of Multiple Criteria Decision Aiding (MCDA) methods to the Choquet integral preference model which permits to represent interaction between considered criteria through the use of a set of non-additive weights called capacity or fuzzy measure. The use of NAROR permits the Decision Maker (DM) to give preference information in terms of preferences between pairs of alternatives with which she is familiar, and relative importance and interaction of considered criteria. The basic idea of NAROR is to consider the whole set of capacities that are compatible with the preference information given by the DM. In fact, the recommendation supplied by NAROR is expressed in terms of necessary preferences, in case an alternative is preferred to another for all compatible capacities, and of possible preferences, in case an alternative is preferred to another for at least one compatible capacity. In the considered case study, several sites for the location of a landfill are analyzed and compared through the use of the NAROR on the basis of different criteria, such as presence of population, hydrogeological risk, interferences on transport infrastructures and economic cost. This paper is the first application of NAROR to a real-world problem, even if not already with real DMs, but with a panel of experts simulating the decision process.

Keywords: Urban and territorial planning; Choquet integral; Indirect preference information; NAROR. 


\section{Introduction}

In contemporary societies, territorial conflicts have become more frequent and widespread than social conflicts; they are often even more disruptive. The conflicts concerning the location of the socalled "undesirable facilities" such as invasive product (motorways, high speed train lines, waste disposal plants, etc.) are characterized by the protest of local communities fighting for the defence of their land from external aggressions (Bobbio 2011; Dente 2014).

These phenomena have been spreading over in Italy in the last decades with tremendous virulence, but similar episodes are observable also in the rest of Europe. There are different interpretations of these territorial conflicts, which are essential to understand the trend and to give, from the point of view of an expert, appropriate decision support tools to the Decision Makers (DMs).

Multiple Criteria Decision Aiding (MCDA, Roy and Bouyssou 1993; Figueira et al. 2005) is a valuable and widely-used tool to support decision-making processes. This approach is particularly useful in the context of sustainability assessment and urban and territorial planning, where a complex and inter-connected range of environmental, social and economic issues must be taken into consideration and where objectives are often competing and conflicting.

Sustainability is often considered in terms of the three pillars of environmental, social and economic considerations. Policies, plans, programmes and projects are subject to specific evaluation procedures, which aim at assessing the overall sustainability of the proposed solutions. In this context, mention can be made to the Environmental Impact Assessment (EIA) and Strategic Environmental Assessment (SEA), which are defined at the European level by the Directives 1997/11/EC and 2001/42/EC, respectively. Both EIA and SEA over time have increasingly considered not only the environmental effects of plans and projects, but also social and economic effects. In this context, neither an economic reductionism nor an ecological one is possible (Munda 2005). Since, in general, economic sustainability has an ecological cost and ecological sustainability has an economic cost, an integrative evaluation framework is needed for tackling sustainability issues properly.

When dealing with sustainability assessment in an integrated way, a critical issue is how to combine the different dimensions in the evaluation framework and it becomes necessary to consider the existence of interaction among the evaluation criteria. In this sense, the principle of compensation cannot be applied in integrated sustainability assessment, where a good performance in one area (for example, low economic costs) cannot be offset by a poor performance in another area (for example, high environmental impacts) (Giove et al. 2011; Bottero et al., 2013). As a consequence, it is required to overcome the conceptual and practical limitations associated with this kind of approach and tackle the problem with a non additive aggregation method that takes into account the potential synergy and redundancy effects among criteria. Indeed, in urban and territorial planning, very often, long-term and negative impacts are the consequence of an underestimation of the interactions between criteria related to economic sustainability and ecological cost as well as to ecological sustainability and economic cost.

The present paper is the first application of the Non Additive Robust Ordinal Regression (NAROR, Angilella et al. 2010a) methodology for the selection of a new landfill location among several alternatives, whose utility is evaluated in terms of the Choquet integral (Choquet 1953; for application of the Choquet integral to MCDA see Grabisch 1996) which permits to represent the 
interactions among criteria, modelled by a set of non-additive weights called capacity or fuzzy measure (for other MCDA approaches to deal with interacting criteria see Figueira et al. 2009 with respect to ELECTRE methods, Corrente et al. 2014a with respect to PROMETHEE methods and Greco et al. 2014 with respect to additive utility functions).

The aim of the analysis is to investigate the contribution that the NAROR approach offers in sustainability assessment of undesirable facilities location problems and more generally in strategic decisions concerning urban and territorial transformations, starting from a real-world problem related to the selection of the best location for a landfill in the Province of Torino (Italy).

The problem of siting an urban waste landfill, and more in general of the location of "undesirable facilities", represents an unstructured problem that needs to be addressed. These problems are characterised by the existence of: 1) multiple actors; 2) multiple perspectives; 3) incommensurable and/or conflicting interests; 4) key uncertainties (Rosenhead and Mingers 2001).

Furthermore, decision problems related to "undesirable facilities" are characterized by decisionmaking contexts particularly difficult and conflicting. For this reason it is highly recommended to use a MCDA methodology only if adequately tested. Many theories and tools are available to face decisional problems (Roy and Słowiński, 2013), but not so many have been really tested in true decisional arenas in the domain of territorial problems. What is most frequently described in the literature are simulations of real decision-making processes.

In the literature the simulations are usually used in two situations:

- in case of lack of data;

- as part of a bigger process that leads at the end to an application in a real situation.

The simulation here illustrated belongs to the second case. Even if it is the description of an application where there has not been a real decision maker, it is based on the data, documentation, procedures and practice of a real world problem. We used a panel of experts lead by the project team. The decision problem was structured according to previous studies and the official sector regulations, exactly as they would be in a real application.

The methodology starts with some preference information given by the DM in terms of, among others:

(1) pairwise preference comparisons of alternatives;

(2) pairwise comparisons of criteria in terms of relative importance;

(3) sign and intensity of interaction between couples of criteria.

Particularly, in the proposed study, several sites for the location of the landfill are analyzed and compared through the use of the NAROR on the basis of different criteria, such as presence of population, hydrogeological risk, agricultural value, interferences on transport infrastructures and economic cost.

In the application domain referring to territorial transformations, it is possible to stress that among the positive aspects of the investigated methodology, a very promising advantage is represented by the fact that the DM is required to give only partial preference information about preferences between alternatives, and importance and interaction between criteria she is enough convinced. In other words, NAROR, as well as Robust Ordinal Regression (ROR, Greco et al. 2008, Figueira et al. 2010, Corrente et al. 2013b, Corrente et al. 2014b) in general, avoids carefully any pressure on the DM for obtaining preference information (e.g. direct assessment of preference parameters such as weights and preference, indifference or veto thresholds) required by the adopted preference 
model but not so clear for the DM. This is highly beneficial for the quality of the recommendation because it is clearly related to the confidence in the preference information given by the DM and it is reasonable to expect that a decision aiding process cannot give enough reliable recommendation if it is based on preference information related to questions not completely clear to the DM. Moreover, NAROR, as any ROR method, gives as result a recommendation that permits to distinguish necessary from possible conclusions, with the necessary conclusions that hold for all sets of preference parameters (in this case capacities) compatible with the DM's preference information, while the possible conclusions hold only for at least one set of preference parameters compatible with the DM's preference information.

These positive aspects are even more appreciable when the Choquet integral preference model is adopted, because it permits to represent the interaction between criteria, which is very important in the decision problem we are considering, at the price of introducing a certain complexity in the number and nature of preferential parameters. In this sense, NAROR represents a very good compromise between the possibility of considering quite complex aspects of the decision problems such as interaction between criteria, and the necessity of dealing with a preference model enough manageable and controllable by the DM, and also by the analyst. Indeed, NAROR maintains not too heavy and easily understandable the preference information required to the DM and avoids, by means of consideration of necessary and possible conclusions, any not sufficiently stable recommendation to be drawn from the decision aiding process.

The plan of the paper is the following. In Section 2, we recall basic concepts of MCDA and NAROR. In Section 3, we present the considered decision problem. In Section 4, we describe the decision aiding processes based on NAROR. Section 5 collects conclusions and discusses possible future developments.

\section{Multiple Criteria Decision Aiding and Non Additive Robust Ordinal Regression}

In MCDA problems (for a comprehensive collection of state of the art surveys on MCDA see Figueira et al. 2005), a set of alternatives $A=\{a, b, c, \ldots\}$ is evaluated on a set of evaluation criteria $G=\left\{g_{1}, \ldots, g_{n}\right\}$ in order to deal with one of the following problems: choice, sorting and ranking. Choice problems consist of choosing a subset (possibly composed of one element only) of alternatives considered the best; sorting problems consist of assigning each alternative to one class of a set of predefined and ordered classes, while ranking problems consist of partially or completely ordering all alternatives from the best to the worst.

Looking at the evaluations of the alternatives on the criteria, without taking into account further preference information and some preference model, it could be only observed if the dominance relation is fulfilled by some pairs of alternatives. An alternative $a$ dominates an alternative $b$ if the evaluations of $a$ are at least as good as the evaluations of $b$ on all criteria and better for at least one criterion. In general, the dominance relation is really poor and leaves many alternatives incomparable. For this reason, in order to get more precise recommendations on the problem at hand, there is the necessity of aggregating the evaluations of the alternatives on the considered criteria through some appropriate preference model representing the DM's preferences. In literature 
the most well-known aggregation methods are the Multiattribute Value Theory (MAVT) (Keeney and Raiffa 1993), the outranking methods (Roy and Bouyssou 1993; Brans and Vincke 1985) and the Decision Rules models based on Dominance Based Rough set Approach (DRSA) (Greco et al, 2001). MAVT assigns to each alternative " $a$ " a real number $U(a)$ being representative of the degree of desirability of $a$ with respect to the problem at hand; outranking methods are based on an outranking relation on the set of alternatives $A$, being a binary relation $S$, in general neither complete nor transitive but only reflexive, such that $a S b$ means that $a$ is at least as good as $b$; DRSA uses a set of "if, ..., then" rules induced from the DM's preference information.

In general, MAVT and outranking methods are based on the mutual independence between criteria (Keeney and Raiffa 1993; Wakker 1989), but, in many real world decision making problems, the evaluation criteria are interacting. Let us suppose, for example, that a DM has to adopt a regional plan and that she takes into account criteria as pollutant emissions, environmental protection of species and cost. On one side, pollutant emissions and environmental protection of species are negatively interacting criteria because, in general, a regional plan having a low level of pollutant emissions has also a good level of environmental protection of species. For this reason, the importance given to this couple of criteria should be lower than the sum of the importance of the two criteria considered separately. On the other side, pollutant emissions and cost are positively interacting criteria because a regional plan having a low level of pollutant emissions but also a low cost is very appreciated by the DM. In this case, the importance of this couple of criteria should be greater than the sum of the importance given to the two criteria separately.

In order to aggregate the evaluations of the alternatives in case of interacting criteria, non-additive integrals are often used in the literature. Among the non-additive integrals, the most known is the Choquet integral (Choquet 1953).

\subsection{The Choquet integral preference model}

A capacity $\mu$ on $2^{G}$ is a set function $\mu: 2^{G} \rightarrow[0,1]$ satisfying normalization $(\mu(\varnothing)=0$ and $\mu(G)=1)$ and monotonicity $(\mu(T) \leq \mu(R)$, for all $T \subseteq R)$ constraints. In an MCDA context, $\mu(R)$ represents the importance comprehensively assigned to criteria from $R \subseteq G$, and in general, the relation

$$
\mu(R)=\sum_{i \in R} \mu(\{i\})
$$

does not hold. Consequently, differently from usual aggregation procedures, using a capacity it is not sufficient to assign a weight to each criterion, but it is necessary to assign a weight to each subset of criteria. The Choquet integral (Choquet 1953) permits to aggregate the performances of an alternative $a \in A$ on criteria from $G$ in an overall evaluation taking into account the importance of criteria represented by the capacity $\mu$. It is defined as follows:

$$
C_{\mu}(a)=\sum_{i=1}^{n}\left[g_{(i)}(a)-g_{(i-1)}(a)\right] \mu\left(N_{i}\right)
$$


where $(\cdot)$ stands for a permutation of the indices of criteria such that: $g_{(1)}(a) \leq g_{(2)}(a) \leq \ldots \leq g_{(n)}(a)$, with $N_{i}=\{(i), \ldots,(n)\}, \mathrm{i}=1,2, \ldots, \mathrm{n}$, and $g_{(0)}=0$.

The value that the Choquet integral assigns to alternative $a$ can be also expressed in the following way,

$$
C_{\mu}(a)=\sum_{T \subseteq G} m(t) \min _{i \in T} g_{i}(a)
$$

where $m: 2^{G} \rightarrow R$ (Shafer 1976) is the Möbius representation of a capacity $\mu$ (Rota 1964) such that

$$
\mu(S)=\sum_{T \subseteq S} m(T)
$$

for all $S \subseteq G$. The formulation of the Choquet integral in terms of the Möbius representation is very meaningful in terms of interaction of criteria. Indeed it can be written as follows

$$
C_{\mu}(a)=\sum_{i \in G} m(\{i\}) g_{i}(a)+\sum_{T \subseteq G} m(T) \min g_{i \in T}(a)
$$

Where:

- $\quad \sum_{i \in G} m(\{i\}) g_{i}(a)$, is the usual weighted sum of the performances $g_{i}(a)$ of $a$ on criteria from $G$, and it is the additive component of the overall evaluation of $a$,

- $\quad \sum_{T \subseteq G} m(T) \min _{i \in T} g_{i}(a)$ is the non-additive component of the overall evaluation of $a$, with $m(T) \min g_{i \in T}(a)$ representing the positive or negative contribution of the interaction between criteria from $\mathrm{T} \subseteq G$.

For the Choquet integral preference model, the main difficult task is to assign the $2^{|G|}-2$ values of $\mu(R), \varnothing \subset R \subset G$ (observe that $\mu(\varnothing)$ and $\mu(G)$ have not to be assigned because, by definition, $\mu(\varnothing)=0$ and $\mu(G)=1)$ ). With the aim of reducing the number of parameters to be elicited and of avoiding a too complex description of the interactions among criteria, in Grabisch (1997) the concept of fuzzy k-additive capacity has been introduced (a capacity is called k-additive if $m(T)=0$ for $T \subseteq G$ such that $|T|>k)$.

Because in an MCDA context, it is easier and more straightforward to consider 2-additive capacities only (since in such case the DMs have to express a preference information on positive and negative interactions between two criteria, neglecting possible interactions among three, four and generally $k$ criteria with $k$ not greater than $n$ ) in the following we shall consider 2 -additive capacities only. However, the methodology we are presenting can be applied to generally nonadditive capacities.

In terms of Möbius representation (Chateauneuf \& Jaffray 1989) and considering a 2-additive capacity, the normalization and the monotonicity constraints can be reformulated as 


$$
\begin{gathered}
m(\emptyset)=0, \sum_{i \in G} m(\{i\})+\sum_{\{i, j\} \subseteq G} m(\{i, j\})=1, \\
\left\{\begin{array}{l}
m(\{i\}) \geq 0, \forall i \in G, \\
m(\{i\})+\sum_{j \in T} m(\{i, j\}) \geq 0, \forall i \in G \text { and } \forall T \subseteq G \backslash\{i\}, T \neq \emptyset
\end{array}\right.
\end{gathered}
$$

while the value that the Choquet integral assigns to $a \in A$ can be computed as follows:

$$
C_{\mu}(a)=\sum_{i \in G} m(\{i\}) g_{i}(a)+\sum_{\{i, j\} \subseteq G} m(\{i, j\}) \min \left\{g_{i}(a), g_{j}(a)\right\} \text {. }
$$

Because in a multicriteria decision problem, the relevance of any criterion $g_{i} \in G$ has to be analyzed considering not only $g_{i}$ as a singleton but also in combination with all other criteria, we recall the definitions of the importance and interaction indices for a couple of criteria.

The importance of criterion $g_{i} \in G$ expressed by the Shapley value (Shapley 1953) in case of a 2additive capacity can be written as follows:

$$
\varphi(\{i\})=m(\{i\})+\sum_{j \in G \backslash\{i\}} \frac{m(\{i, j\})}{2} .
$$

The interaction index (Murofushi and Soneda 1993) expressing the sign and the magnitude of the interaction in a couple of criteria $\{i, j\} \subseteq G$, in case of a 2 -additive capacity $\mu$, is given by:

$$
\varphi(\{i, j\})=m(\{i, j\})
$$

\subsection{Robust Ordinal Regression and NAROR}

In the following, we recall the basic concepts of NAROR (Angilella et al. 2010a).

As explained in the section above, in order to apply the Choquet integral one has to define several parameters $\left(2^{|G|}-2\right.$ values defining the capacity $\left.\mu\right)$. To get these parameters, direct or indirect techniques can be used. In the direct technique, the DM is able to provide values for each parameter of the model, while in the indirect technique the DM is able to provide some preferences in terms of comparisons between alternatives or criteria from which to elicit parameters compatible with these preferences. Some indirect techniques have been proposed in Angilella et al. 2004 and Marichal \& Roubens 2000 (for an extensive review on the topic, see also Grabisch et al. 2008 and Grabisch \& Labreuche 2010).

In case of indirect information, the DM is expected to provide the following information with respect to a subset of alternatives $A^{R} \subseteq A$ :

- a partial preorder $\succeq$ on $A^{R}$ whose meaning is: for $a^{*}, b^{*} \in A^{R}$

$$
a^{*} \succeq b^{*} \Leftrightarrow \text { " } a * \text { is at least as good as } b^{*} \text { "; }
$$

- a partial preorder $\succeq^{*}$ on $A^{R} x A^{R}$, whose meaning is: for $a^{*}, b^{*}, c^{*}, d^{*} \in A^{R}$, $\left(a^{*}, b^{*}\right) \succeq^{*}\left(c^{*}, d^{*}\right) \Leftrightarrow$ " $a *$ is preferred to $b^{*}$ at least as much as $c^{*}$ is preferred to $d^{*}$ "; 
- a partial preorder $\succeq_{1}$ on $G$, whose meaning is: for $g_{i}, g_{j} \in G$

$$
g_{i} \succeq_{1} g_{j} \Leftrightarrow \text { "criterion } g_{i} \text { is at least as important as criterion } g_{j} \text { "; }
$$

- a partial preorder $\succeq_{1}^{*}$ on $G x G$, whose meaning is: for $g_{i}, g_{j}, g_{k}, g_{l} \in G$,

$$
\begin{aligned}
\left(g_{i}, g_{j}\right) \succeq_{1} *\left(g_{k}, g_{l}\right) \Leftrightarrow & \text { "the difference of importance between criteria } g_{i} \text { and } g_{j} \text { is no lower than the } \\
& \text { difference of importance between criteria } g_{k} \text { and } g_{l} \text { "; }
\end{aligned}
$$

- the sign of the interaction between criteria $g_{i}$ and $g_{j}$, with $g_{i}, g_{j} \in G$ :

(a) $g_{i}$ and $g_{j}$ are positively interacting,

(b) $g_{i}$ and $g_{j}$ are negatively interacting.

Note that we can introduce $\sim$ (indifference) and $>$ (preference) so as $\sim^{*}$ and $>^{*}$ as the symmetric and the asymmetric part of $\succeq$ and $\succeq^{*}$ respectively; i.e. $a^{*} \sim b^{*}$ iff $a^{*} \succeq b^{*}$ and $b^{*} \succeq a^{*}$ while $a^{*}>b^{*}$ iff $a^{*} \succeq b^{*}$ and $\operatorname{not}\left(b^{*} \succeq a^{*}\right)$.

All these preference information are translated by inequality constraints, that together with the normalization and monotonicity constraints constitutes the following set of constraints $E^{A R}$

$$
\left.\begin{array}{l}
C_{\mu}\left(a^{*}\right) \geq C_{\mu}\left(b^{*}\right) \text { if } a^{*} \gtrsim b^{*} \\
C_{\mu}\left(a^{*}\right) \geq C_{\mu}\left(b^{*}\right)+\varepsilon \text { if } a^{*} \succ b^{*}, \\
C_{\mu}\left(a^{*}\right)=C_{\mu}\left(b^{*}\right) \text { if } a^{*} \sim b^{*}, \\
C_{\mu}\left(a^{*}\right)-C_{\mu}\left(b^{*}\right) \geq C_{\mu}\left(c^{*}\right)-C_{\mu}\left(d^{*}\right)+\varepsilon \text { if }\left(a^{*}, b^{*}\right) \succ^{*}\left(c^{*}, d^{*}\right), \\
C_{\mu}\left(a^{*}\right)-C_{\mu}\left(b^{*}\right)=C_{\mu}\left(c^{*}\right)-C_{\mu}\left(d^{*}\right) \text { if }\left(a^{*}, b^{*}\right) \sim^{*}\left(c^{*}, d^{*}\right), \\
\varphi(\{i\}) \geq \varphi(\{j\}) \text { if } i \gtrsim_{1} j, \\
\varphi(\{i\})=\varphi(\{j\}) \text { if } i \sim_{1} j, \\
\varphi(\{i, j\}) \geq \varepsilon, \text { if criteria } i \text { and } j \text { are synergic with } i, j \in G, \\
\varphi(\{i, j\}) \leq-\varepsilon, \text { if criteria } i \text { and } j \text { are redundant with } i, j \in G, \\
m(\{\varnothing\})=0, \sum_{i \in G} m(\{i\})+\sum_{\{i, j\} \subseteq G} m(\{i, j\})=1, \\
m(\{i\}) \geq 0, \forall i \in G, \\
m(\{i\})+\sum_{j \in T} m(\{i, j\}) \geq 0, \forall i \in G, \text { and } \forall T \subseteq G \backslash\{i\}, T \neq \emptyset
\end{array}\right\}
$$

where $\varepsilon$ is an auxiliary variable used to transform the strict inequality constraints in weak inequality constraints. If $\mathrm{E}^{\mathrm{AR}}$ is feasible and $\varepsilon^{*}>0$, where $\varepsilon^{*}=\max \varepsilon$ subject to $\mathrm{E}^{\mathrm{AR}}$, then there exists at least 
one model compatible with the DM's preferences, otherwise one could check the reason of the incompatibility by using one of the techniques described in Mousseau et al. 2003.

The indirect technique is the most used because it needs less cognitive effort from the DM who is asked to provide only some preferences on a small subset of alternatives that she knows well. In general, there could exist more than one model compatible with the preferences provided by the DM. Each of these models gives the same recommendations on the examples provided by the DM but it can give different recommendations on the others alternatives not provided as example. For this reason, the choice of only one of these models, among all the compatible ones, could be considered arbitrary or meaningless. In this perspective Greco et al. (2008) introduced ROR to take into account the whole set of models compatible with the preference information provided by the DM building two preference relations, one necessary and one possible on the set of alternatives $A$. The necessary preference relation holds between two alternatives $a, b \in A$ (denoted by $a \succeq^{\mathrm{N}} b$ ) if $a$ is at least as good as $b$ for all compatible models, while the possible preference relation holds between $a$ and $b$ (denoted by $a \succeq^{\mathrm{P}} b$ ) if $a$ is at least as good as $b$ for at least one of these compatible models. ROR has been already applied to value functions (Greco et al., 2008; Kadziński et al. 2012a; Corrente et al. 2012), outranking methods (Greco et al. 2011a; Kadziński et al. 2012b; Corrente et al. 2013a), and Choquet integral (Angilella et al. 2010a) which corresponds to NAROR. In this context, we shall describe how to compute the necessary and possible preference relations in the NAROR method.

Given the following sets of constraints,

we have that:

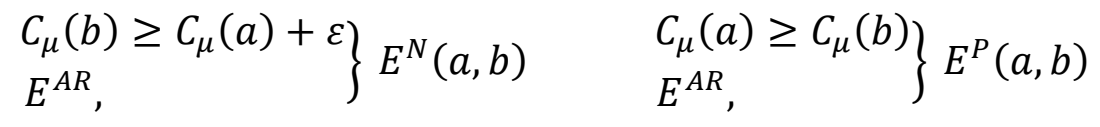

- $\quad a \succeq^{\mathrm{N}} b$ if $\mathrm{E}^{\mathrm{N}}(a, b)$ is infeasible or if $\varepsilon^{\mathrm{N}} \leq 0$ where $\varepsilon^{\mathrm{N}}=\max \varepsilon$ subject to $\mathrm{E}^{\mathrm{N}}(a, b)$,

- $a \succeq^{\mathrm{P}} b$ if $\mathrm{E}^{\mathrm{P}}(a, b)$ is feasible and $\varepsilon^{\mathrm{P}}>0$ where $\varepsilon^{\mathrm{P}}=\max \varepsilon$ subject to $\mathrm{E}^{\mathrm{P}}(a, b)$.

In some cases, and also in our approach, one needs to assign a real number to the utility evaluation of each alternative in order to obtain a complete ranking of the alternatives. For this reason, based on the results of the ROR, among all the compatible models one can compute the most representative value function being that one maximizing the difference in the performance of two alternatives $a$ and $b$ for which $a \succeq^{\mathrm{N}} b$ but $\operatorname{not}\left(b \succeq^{\mathrm{N}} a\right)$, and minimizing the difference in the performances of two alternatives $a$ and $b$ such that $a \succeq^{\mathrm{P}} b$ and $b \succeq^{\mathrm{P}} a$ (Figueira et al. 2008; Angilella et al. 2010b; Kadziński et al. 2013; Kadziński et al. 2012b; Greco et al. 2011 b; Kadziński et al. 2011).

The considered procedure is composed of two steps:

(a) Solving the following optimization problem:

$$
\begin{aligned}
& \text { max } \varepsilon \text { subject to } \\
& \left.\begin{array}{l}
C_{\mu}(a) \geq C_{\mu}(b)+\varepsilon \text { if } a \gtrsim^{N} b \text { and } \operatorname{not}\left(b \gtrsim^{N} a\right), \\
E^{A R}
\end{array}\right\} E_{1}
\end{aligned}
$$


(b) Denoted by $\varepsilon_{1}$ the optimal value of $\varepsilon$ obtained in the previous step, solving the following optimization problem:

$\min \delta$ s.t.

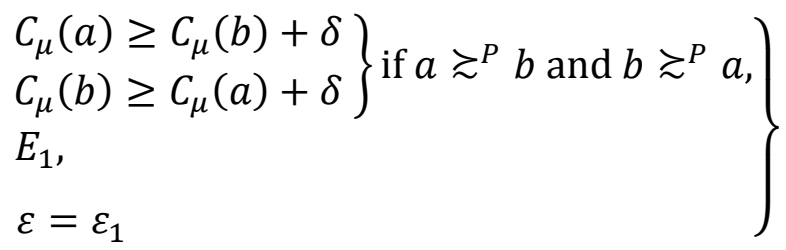

\section{Presentation of the decision problem}

The decision problem presented in the paper concerns the choice of the most suitable location for a municipal solid waste landfill, which has to be constructed in the Province of Torino (Italy).

The work conducted in this paper is the simulation of a real-world decision making problem and it is based on a scientific study that was developed by the Provincial Administration (ATO-R 2007). This means that all alternatives and criteria that we took into account in the considered study have not been chosen by ourselves but have been decided in the real case we are dealing with. For this reason, when we speak of "the original case study" we refer to the formulation of the problem and to the choice of the alternatives, criteria and parameters that have been decided without our presence.

In this respect it is worth underlying that we did not have any interaction with a real DM but we supposed to be the DM who had to take the decision. The aim of this study is to show how NAROR could be applied to a real world case in order to obtain robust recommendations.

A preliminary environmental analysis of the territory under examination has been developed and 39 sites have been identified as potentially suitable for the location of the landfill. Particularly, all the available information concerning the environmental system and territorial context of these locations has been organized according to a qualitative/quantitative approach based on specific indicators.

It is important to emphasize that the European Directive in the field of landfill or waste (Directive 1999/31/EC) is very restrictive with regard to technical and operational requirements for landfills. The purpose of the Directive is in fact to prevent or to minimize the negative environmental impacts, in particular the pollution of surface water, groundwater, soil, atmosphere and risks on human health.

In order to obtain the authorization for the construction and operation of a landfill, the project has to meet all the requirements set by the legislation concerning:

- Localization;

- Protection of the environmental system;

- Water control and leachate management;

- Protection of soil and water;

- Gas monitoring;

- Problems and risks;

- Stability;

- Physical protection of equipment; 
- Availability of equipment and staff;

- Methods and criteria of dumping.

According to the Regional Law 24/2002 (Regulations for waste management), the Provincial Authorities are responsible for the detection of suitable areas for the location of waste disposal and for the recovery of municipal waste. Particularly, the procedure for finding a suitable site to host waste disposal facilities is articulated into 5 phases:

$>$ PHASE 0 - "Regional Planning" (competence of the Regional Authority)

○ Regional Waste Management Plan

- Definition of criteria for the detection of areas not suitable for the location of waste treatment and disposal.

$>$ PHASE 1 "Localization at the macro level" (competence of the Provincial Authority)

- Provincial Program of Waste Management

- Legal provisions of regional criteria

○ Mapping the "unsuitable areas" and "potentially suitable areas"

- Criteria definition for the localization at the micro level.

$>$ PHASE 2 - "Localization at the micro level" (competence of local authorities in charge for waste management - ATOR) :

- Application of the localization criteria at the micro level on potentially suitable areas, selected in phase 1

- Identification of suitable sites

○ Definition of environmental compensation measures.

$>$ PHASE 3 - "project" (competence of the specific bodies in charge for the construction of the plants):

○ Project

- Environmental impact studies.

$>$ PHASE 4 - "Authorization" within the jurisdiction of the Provincial Authority:

- Assessment of the environmental impact study

- Permission to build and operate.

In this paper, we propose the use of the NAROR methodology for addressing the decision problem related to Phase 2 where a shortlist of suitable sites has already been identified and has to be discussed with representatives of the area and municipalities. For the purpose of the application, we simulated the decision aiding process in order to explore the use of the NAROR methodology for supporting the choice of the best location for hosting the landfill. The decision of applying NAROR to the case is linked to the fact that few preference information based on sound technical arguments are enough to compare large numbers of cases and to identify the best solutions for the decision problem.

\subsection{Description of the criteria}

The problem we are considering is the selection of the most compatible site for the location of a landfill. 
Table 1 gives a description of the criteria that have been taken into account in the considered decision making problem, showing if the criteria have to be maximized, denoted by " $\uparrow$ ”, or minimized, denoted by “ $\downarrow$ ”.

It is necessary to highlight that the criteria considered in the present application reflect the requirements coming from the legislative framework in the context of Environmental Impact Assessment (first of all, the European Directive 11/97) and arise from the aforementioned scientific study developed by ATOR (2007).

Table 1 Criteria considered in the evaluation

\begin{tabular}{|c|c|c|c|}
\hline Criteria & Name & Description & $\begin{array}{l}\text { Assessment } \\
\text { direction }\end{array}$ \\
\hline $\mathrm{C} 1$ & Population & $\begin{array}{l}\text { The criterion considers the population in each site, with reference } \\
\text { both to the inhabitants and to the people that work in the area. }\end{array}$ & $\downarrow$ \\
\hline $\mathrm{C} 2$ & Vulnerability & $\begin{array}{l}\text { The criterion assesses the vulnerability of the groundwater aquifer, } \\
\text { considering also the measured depth (meters) of the water table that } \\
\text { lies under each site. }\end{array}$ & $\downarrow$ \\
\hline $\mathrm{C} 3$ & $\begin{array}{l}\text { Agricultural } \\
\text { value }\end{array}$ & $\begin{array}{l}\text { The criterion analyzes the presence of valuable agricultural crops in } \\
\text { the area of each site and the number of organic farms in the area } \\
\text { surrounding each site. }\end{array}$ & $\uparrow$ \\
\hline $\mathrm{C} 4$ & $\begin{array}{l}\text { Interference } \\
\text { with traffic }\end{array}$ & $\begin{array}{l}\text { The criterion gives the level of use of road infrastructures in the } \\
\text { area surrounding the plant, thus estimating the potential } \\
\text { interference caused by the landfill. }\end{array}$ & $\downarrow$ \\
\hline $\mathrm{C} 5$ & $\begin{array}{l}\text { Operating } \\
\text { costs }\end{array}$ & $\begin{array}{l}\text { The criterion examines the costs for the management and the } \\
\text { operation of the plant in each of the considered sites. In particular, } \\
\text { the costs are related to the economic expenses for linking the } \\
\text { landfill with the main ecologic services pole located in the area. }\end{array}$ & $\downarrow$ \\
\hline
\end{tabular}

The criterion $\mathrm{C} 1$ represents the population in the surrounding area of each site, considering both the permanent and the temporary presences.

With reference to criterion C2-Vulnerability, it considers the risk for the aquifer related to each site. This has been measured through the GOD method (Groundwater hydraulic confinement/Overlaying strata/Depth to groundwater table; Foster 1987).

Among the many approaches that have been developed to evaluate aquifer vulnerability, the GOD method is one of the most consolidated and applied. In particular, it is a rating system that assesses vulnerability by means of three variables: groundwater occurrence $(\mathrm{G})$, overall lithology of aquifer 
(O) and depth to groundwater table (D). According to this classification, five classes are identified where class 5 indicates an highly vulnerable aquifer and class 1 identifies a very low vulnerable aquifer.

As far as criterion C3-Agricultural value is considered, the raw data related to the indicators have been aggregated in a final index through a specific scheme. Particularly, this scheme allows the indicators related to number of farms and land use capacity to be combined, providing a final index measured in the 0-10 scale where the value 0 indicates the less suitable site and the value 10 the most suitable site for hosting the plant. Table 4 represents the scheme that has been used for the evaluation: the scheme crosses the values of land use capacity with the number of farms in the area surrounding each site. As it is possible to see, the less the number of farms and the higher the level of land use capacity (which represents low quality soils), the higher the value of the final suitability index. For example, let us consider a site described by a number of farms equal to 2 (second row of Table 4) and a value of land use capacity equal to 3 (third column of Table 4). The final index for this specific site will be 5 (representing a medium suitability) as indicated in correspondence to the second row/third column of Table 4.

With reference to criterion C4-Interference with traffic, mention has to be made to the fact that the degree of interference with the traffic has been estimated by creating different classes based on the level of use (measured as distance covered in meters on the roads) of municipal and local roads, on the level of use of national and regional roads and on the use of highways. Table 5 provides the scheme that has been used for the creation of the classes, where class 6 is the worst one and class 1 is the best one. By observing the table it is possible to notice that the most important aspect is the level of use of municipal and local roads since these are the more sensitive to changes in traffic due to heavy lorries circulation.

Finally, criterion C5 considers the economic costs related to the operation and management activities of the plant in each one of the considered site.

\subsection{Construction of the evaluation matrix}

As already anticipated, 39 alternative sites were considered in the study carried out by the Province and the original data used for the evaluation are represented in Table 2. 


\begin{tabular}{|c|c|c|c|c|c|c|c|c|c|c|c|c|c|}
\hline \multirow[b]{3}{*}{ SITE } & \multicolumn{6}{|c|}{ C1 POPULATION } & \multirow{3}{*}{$\begin{array}{c}\text { C2 } \\
\text { VULNERABILITY } \\
\begin{array}{c}\text { GOD vulnerability } \\
\text { index } \\
\text { (class) }\end{array}\end{array}$} & \multicolumn{2}{|c|}{\begin{tabular}{|c|} 
C3 \\
AGRICULTURAL \\
VALUE
\end{tabular}} & \multicolumn{3}{|c|}{$\begin{array}{c}\text { C4 INTERFERENCE WITH } \\
\text { TRAFFIC }\end{array}$} & \multirow{3}{*}{\begin{tabular}{|c|} 
C5 \\
OPERATING \\
COSTS \\
$€$
\end{tabular}} \\
\hline & \multicolumn{3}{|c|}{ Permanent } & \multicolumn{3}{|c|}{ Transitory } & & Land & & & National & & \\
\hline & $\begin{array}{c}0-500 \\
\mathrm{~m}\end{array}$ & $\begin{array}{c}500-1000 \\
\mathrm{~m}\end{array}$ & $\begin{array}{c}1000-1500 \\
\mathrm{~m}\end{array}$ & $\begin{array}{c}0-500 \\
\mathrm{~m}\end{array}$ & $\begin{array}{c}500-1000 \\
M\end{array}$ & $\begin{array}{c}1000-1500 \\
\mathrm{~m}\end{array}$ & & $\begin{array}{c}\text { use } \\
\text { capacity } \\
\text { (class) }\end{array}$ & $\begin{array}{c}\text { Farms } \\
\text { (number) }\end{array}$ & $\begin{array}{l}\text { Highways } \\
\text { (m) }\end{array}$ & $\begin{array}{c}\text { and } \\
\text { regional } \\
\text { roads }(\mathbf{m})\end{array}$ & $\begin{array}{l}\text { and local } \\
\text { roads }(\mathbf{m})\end{array}$ & \\
\hline Air_A & 57 & 178 & 1,226 & 15 & 1,006 & 463 & 3 & 2 & 0 & 0 & 9,850 & 1,200 & $3,768,283$ \\
\hline Air_B & 33 & 1,297 & 1,840 & 6 & 1,298 & 453 & 3 & 2 & 1 & 0 & 9,850 & 600 & $3,561,756$ \\
\hline Bri_A & 62 & 444 & 850 & 5 & 587 & 382 & 4 & 2 & 2 & 0 & 6,750 & 0 & $2,186,531$ \\
\hline Bur_A & 36 & 224 & 607 & 10 & 93 & 238 & 3 & 1 & 2 & 0 & 8,000 & 0 & $2,864,316$ \\
\hline Bur_B & 17 & 63 & 543 & 1 & 3 & 221 & 3 & 1 & 1 & 0 & 6,500 & 0 & $2,050,974$ \\
\hline Caf_A & 62 & 444 & 850 & 193 & 182 & 318 & 3 & 3 & 4 & 0 & 14,650 & 500 & $5,179,629$ \\
\hline Cav_A & 61 & 137 & 186 & 9 & 25 & 35 & 4 & 3 & 0 & 0 & 14,550 & 2,100 & $5,695,972$ \\
\hline Crc_A & 15 & 117 & 213 & 1 & 5 & 9 & 3 & 1 & 0 & 0 & 9,200 & 0 & $3,131,470$ \\
\hline Cum_A & 40 & 468 & 1,351 & 11 & 221 & 452 & 2 & 4 & 2 & 0 & 7,100 & 750 & $2,782,982$ \\
\hline Cum_B & 20 & 102 & 191 & 8 & 56 & 84 & 3 & 2 & 0 & 4,900 & 3,350 & 3,200 & $3,905,984$ \\
\hline Frs_A & 15 & 40 & 85 & 4 & 9 & 494 & 3 & 4 & 0 & 0 & 7,100 & 1,300 & $2,856,088$ \\
\hline Frs_B & 23 & 36 & 133 & 4 & 67 & 492 & 3 & 3 & 0 & 0 & 6,650 & 1,350 & $2,810,093$ \\
\hline Mac_A & 33 & 572 & 457 & 8 & 199 & 231 & 4 & 3 & 2 & 0 & 6,650 & 1,550 & $2,918,539$ \\
\hline Non_A & 23 & 109 & 205 & 4 & 30 & 148 & 3 & 2 & 0 & 12,900 & 5,350 & 2,300 & $7,038,463$ \\
\hline Osa_A & 64 & 250 & 667 & 2 & 71 & 496 & 4 & 2 & 5 & 0 & 6,200 & 1,250 & $2,566,091$ \\
\hline Pin_A & 28 & 144 & 471 & 4 & 17 & 69 & 4 & 2 & 1 & 0 & 2,750 & 1,400 & 480,037 \\
\hline Pin_B & 36 & 234 & 1,202 & 6 & 130 & 641 & 4 & 2 & 2 & 0 & 5,500 & 1,100 & $2,105,197$ \\
\hline Pis_A & 19 & 315 & 1,064 & 3 & 93 & 1,146 & 3 & 2 & 2 & 4,900 & 3,350 & 500 & $2,976,568$ \\
\hline Ssp_A & 192 & 532 & 3,245 & 72 & 164 & 1,161 & 4 & 2 & 2 & 0 & 5,194 & 500 & $1,613,938$ \\
\hline Vig_A & 31 & 105 & 112 & 1 & 9 & 10 & 4 & 2 & 1 & 0 & 15,000 & 0 & $5,127,995$ \\
\hline Vil_A & 25 & 293 & 115 & 3 & 10 & 12 & 4 & 2 & 0 & 0 & 16,500 & 2,700 & $6,573,754$ \\
\hline Vol_A & 30 & 102 & 1,007 & 11 & 23 & 411 & 3 & 2 & 2 & 12,900 & 4,250 & 1,500 & $6,384,429$ \\
\hline
\end{tabular}




\begin{tabular}{|c|c|c|c|c|c|c|c|c|c|c|c|c|c|}
\hline Air_2 & 31 & 1,228 & 1,500 & 304 & 1,152 & 616 & 3 & 2 & 2 & 0 & 9,850 & 600 & $3,681,756$ \\
\hline Air_3 & 9 & 358 & 1,607 & 760 & 631 & 170 & 3 & 2 & 0 & 6,000 & 3,350 & 1,600 & $3,389,642$ \\
\hline Air_4 & 13 & 87 & 1,599 & 36 & 1,316 & 175 & 3 & 2 & 0 & 6,000 & 3,350 & 1,600 & $3,389,642$ \\
\hline Non_1 & 7 & 114 & 121 & 0 & 13 & 356 & 3 & 3 & 0 & 17,720 & 3,850 & 0 & $7,389,576$ \\
\hline Fros_1 & 27 & 207 & 558 & 9 & 109 & 1,010 & 3 & 2 & 1 & 0 & 4,650 & 600 & $1,373,188$ \\
\hline Fros_2 & 43 & 274 & 601 & 28 & 410 & 1,092 & 3 & 2 & 0 & 0 & 4,650 & 600 & $1,373,188$ \\
\hline Pin_1 & 47 & 256 & 191 & 9 & 90 & 180 & 3 & 1 & 2 & 0 & 3,350 & 1,350 & $1,074,963$ \\
\hline Pin_2 & 32 & 102 & 391 & 9 & 66 & 50 & 3 & 1 & 2 & 0 & 3,350 & 1,000 & 885,183 \\
\hline Pin_3 & 26 & 186 & 273 & 8 & 91 & 20 & 3 & 1 & 2 & 0 & 3,350 & 1,700 & $1,264,742$ \\
\hline Pin_4 & 42 & 102 & 899 & 2 & 10 & 443 & 2 & 2 & 3 & 0 & 3,350 & 1,600 & $1,454,522$ \\
\hline Pin_5 & 36 & 130 & 279 & 2 & 10 & 84 & 2 & 2 & 3 & 0 & 3,350 & 1,600 & $1,454,522$ \\
\hline Rol_1 & 72 & 210 & 739 & 63 & 729 & 694 & 3 & 2 & 0 & 0 & 5,050 & 350 & $1,454,522$ \\
\hline Sca_1 & 26 & 129 & 336 & 2 & 12 & 39 & 3 & 2 & 3 & 0 & 9,250 & 600 & $3,355,219$ \\
\hline Sca_2 & 16 & 123 & 315 & 0 & 10 & 32 & 3 & 2 & 3 & 0 & 9,250 & 600 & $3,355,219$ \\
\hline Sca_3 & 12 & 86 & 437 & 1 & 11 & 77 & 3 & 2 & 3 & 0 & 9,250 & 600 & $3,355,219$ \\
\hline Sca_4 & 12 & 71 & 227 & 1 & 4 & 10 & 3 & 1 & 0 & 0 & 9,200 & 0 & $3,131,470$ \\
\hline Vol_2 & 34 & 34 & 482 & 113 & 148 & 203 & 3 & 2 & 0 & 12,550 & 4,300 & 500 & $5,936,932$ \\
\hline
\end{tabular}


In order to obtain some recommendations on the considered problem, the data presented in Table 2 have to be aggregated. In fact, as one can notice, the five criteria are structured in a hierarchical way. For example, criterion population has two subcriteria (permanent and transitory population) and each of these two subcriteria has three subsubcriteria (population in $0-500 \mathrm{~m}$, population in 500$1000 \mathrm{~m}$ and population in 1000-1500m). Analogously, criteria agricultural value and interference with traffic have a hierarchical structure. Agricultural value has two subcriteria (land use capacity and number of farms present in the considered area), while criterion interference with traffic has three subcriteria taking into account the presence of highways, national and regional roads, and municipal and local roads.

Regarding criterion $\mathrm{C} 1$, to obtain a unique value taking into account the six evaluations on the considered subcriteria, a weighted sum has been applied using the weights presented in Table 3 in the original study.

Table 3: Data set normalization

\begin{tabular}{|c|c|c|c|c|}
\hline \multicolumn{2}{|c|}{ Type of population } & \multicolumn{3}{|c|}{ Distance from the site } \\
\hline Permanent & Transitory & $500[\mathrm{~m}]$ & $1000[\mathrm{~m}]$ & $1500[\mathrm{~m}]$ \\
\hline 0.60 & 0.40 & 0.50 & 0.30 & 0.20 \\
\hline
\end{tabular}

This means that, in the original study, the evaluation of the site Air_A on criterion C1 has been obtained as follows:

$\mathrm{g}_{\mathrm{C} 1}\left(\mathbf{A i r} \_\mathbf{A}\right)=[57 * 0.50+178 * 0.30+1,226 * 0.20] * 0.60+[15 * 0.50+1,006 * 0.30+463 * 0.20] * 0.40=357.02$.

Regarding criteria agricultural value (C3) and interference with traffic (C4), the aggregation has been done as in literature (Glasson et al., 2013) following the rules described in Tables 4 and 5.

Table 4 Evaluation scheme for the criterion related to the agricultural value

\begin{tabular}{|c|c|c|c|c|c|}
\hline & \multicolumn{4}{|c|}{ Land use capacity } \\
\hline & & 1 & 2 & 3 & 4 \\
\hline \multirow{4}{*}{$\underset{\tilde{E}}{\tilde{E}}$} & $\geq 3$ & 0 & 2 & 4 & 7 \\
\hline & 2 & 1 & 3 & 5 & 8 \\
\hline & 1 & 3 & 5 & 6 & 9 \\
\hline & 0 & 7 & 8 & 9 & 10 \\
\hline
\end{tabular}


Table 5 Classes of interference with traffic

\begin{tabular}{|c|c|c|c|}
\hline $\begin{array}{c}\text { Level of use of municipal } \\
\text { and local roads (m) }\end{array}$ & $\begin{array}{c}\text { Level of use of national } \\
\text { and regional roads (m) }\end{array}$ & Use of highways (yes/no) & Class \\
\hline$\geq 1500$ & $>10000$ & NO & 6 \\
\hline$\geq 1500$ & $<10000$ & NO & 5 \\
\hline$\geq 1500$ & $<10000$ & YES & 4 \\
\hline$<1500$ & $\geq 10000$ & NO & 3 \\
\hline$<1500$ & $<10000$ & NO & 2 \\
\hline$<1500$ & $<10000$ & YES & 1 \\
\hline
\end{tabular}

For example, referring to the evaluations of site Air_A on land use capacity (2) and number of farms in the area (0), from Table 4 we get that the evaluation of Air_A on criterion agricultural value will be equal to 8 .

Analogously, taking into account the evaluations of Air_A with respect to presence of highways (NO), national and regional roads $(9,850 \mathrm{~m})$ and municipal and local roads $(1,200 \mathrm{~m})$, by looking at Table 5 the global evaluation of Air_A on criterion interference with traffic will be equal to 2 (fifth line of Table 5).

We would like to underline again that the aggregations shown have been performed in the original case study.

After performing the considered aggregations on criteria $\mathrm{C} 3$ and $\mathrm{C} 4$ (but no on criterion $\mathrm{C} 1$ ), the new evaluations are shown in Table 6.

Table 6 Evaluation Table

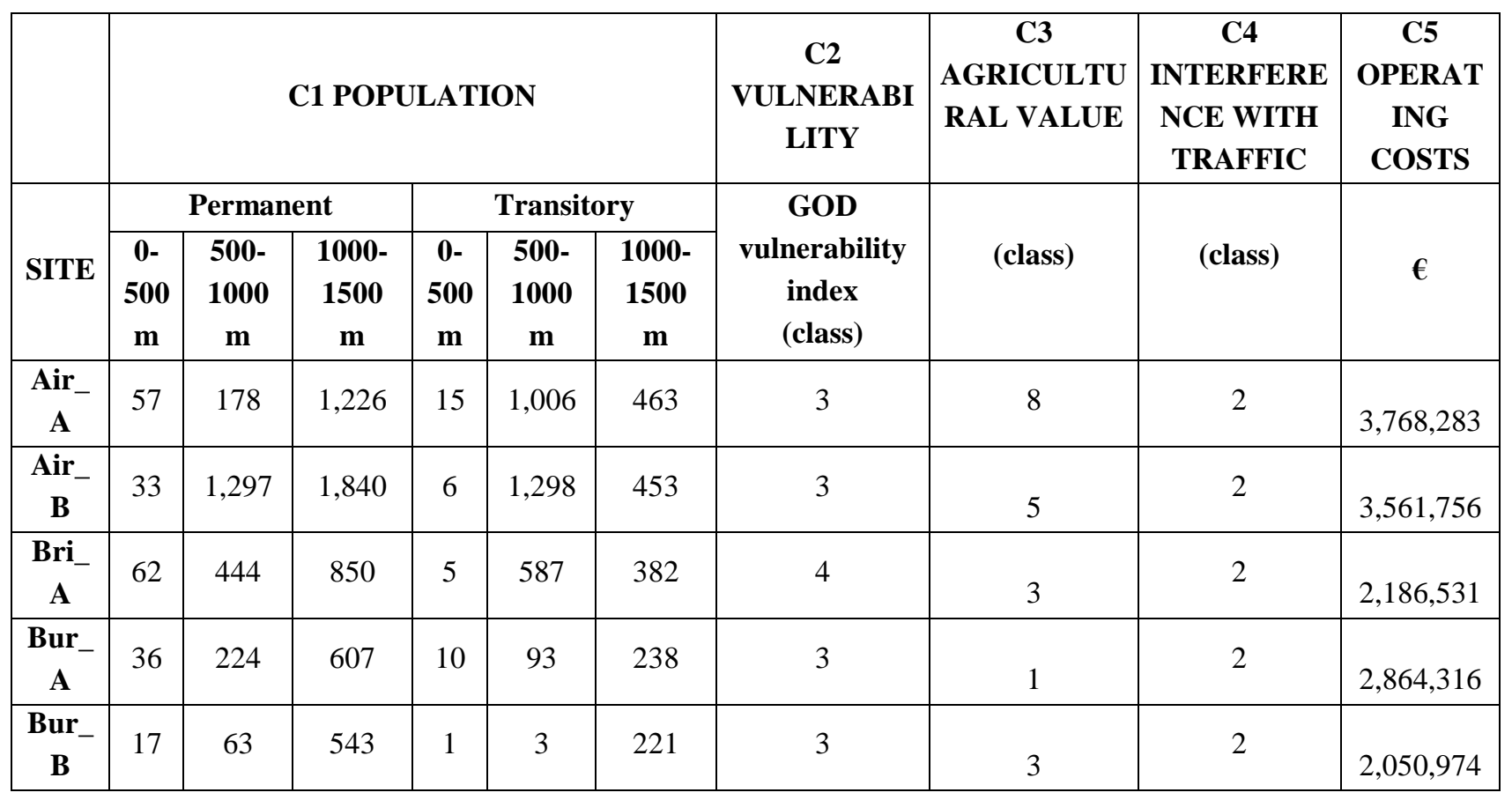




\begin{tabular}{|c|c|c|c|c|c|c|c|c|c|c|}
\hline $\begin{array}{c}\text { Caf_ }_{-} \\
\text {A }\end{array}$ & 62 & 444 & 850 & 193 & 182 & 318 & 3 & 4 & 3 & $5,179,629$ \\
\hline $\begin{array}{c}\mathbf{C a v}_{-} \\
\mathrm{A}\end{array}$ & 61 & 137 & 186 & 9 & 25 & 35 & 4 & 9 & 6 & $5,695,972$ \\
\hline $\begin{array}{c}\mathrm{Crc}_{-} \\
\mathrm{A}\end{array}$ & 15 & 117 & 213 & 1 & 5 & 9 & 3 & 7 & 2 & $3,131,470$ \\
\hline $\begin{array}{c}\text { Cum } \\
\text { _A }\end{array}$ & 40 & 468 & 1,351 & 11 & 221 & 452 & 2 & 8 & 2 & $2,782,982$ \\
\hline $\begin{array}{c}\text { Cum } \\
\text { _B }\end{array}$ & 20 & 102 & 191 & 8 & 56 & 84 & 3 & 8 & 4 & $3,905,984$ \\
\hline $\begin{array}{c}\text { Frs }_{-} \\
\text {A }\end{array}$ & 15 & 40 & 85 & 4 & 9 & 494 & 3 & 10 & 2 & $2,856,088$ \\
\hline $\begin{array}{c}\text { Frs }_{-} \\
\text {B }\end{array}$ & 23 & 36 & 133 & 4 & 67 & 492 & 3 & 9 & 2 & $2,810,093$ \\
\hline $\begin{array}{c}\mathbf{M a c}_{-} \\
\mathbf{A}\end{array}$ & 33 & 572 & 457 & 8 & 199 & 231 & 4 & 5 & 2 & $2,918,539$ \\
\hline $\begin{array}{c}\text { Non }_{-} \\
\text {A }\end{array}$ & 23 & 109 & 205 & 4 & 30 & 148 & 3 & 8 & 4 & $7,038,463$ \\
\hline $\begin{array}{c}\mathrm{Osa}_{-} \\
\mathbf{A}\end{array}$ & 64 & 250 & 667 & 2 & 71 & 496 & 4 & 2 & 2 & $2,566,091$ \\
\hline $\begin{array}{c}\text { Pin }_{-} \\
\text {A }\end{array}$ & 28 & 144 & 471 & 4 & 17 & 69 & 4 & 5 & 2 & 480,037 \\
\hline $\begin{array}{c}\text { Pin }_{\text {_ }} \\
\text { B }\end{array}$ & 36 & 234 & 1,202 & 6 & 130 & 641 & 4 & 3 & 2 & $2,105,197$ \\
\hline $\begin{array}{c}\text { Pis }_{-} \\
\text {A }\end{array}$ & 19 & 315 & 1,064 & 3 & 93 & 1,146 & 3 & 3 & 1 & $2,976,568$ \\
\hline $\begin{array}{c}\text { Ssp }_{-} \\
\text {A }\end{array}$ & 192 & 532 & 3,245 & 72 & 164 & 1,161 & 4 & 3 & 2 & $1,613,938$ \\
\hline $\begin{array}{c}\text { Vig }_{-} \\
\text {A }\end{array}$ & 31 & 105 & 112 & 1 & 9 & 10 & 4 & 5 & 3 & $5,127,995$ \\
\hline $\begin{array}{c}\text { Vil__ } \\
\text { A }\end{array}$ & 25 & 293 & 115 & 3 & 10 & 12 & 4 & 8 & 6 & $6,573,754$ \\
\hline $\begin{array}{c}\text { Vol_ } \\
\text { A }\end{array}$ & 30 & 102 & 1,007 & 11 & 23 & 411 & 3 & 3 & 1 & $6,384,429$ \\
\hline Air_2 & 31 & 1,228 & 1,500 & 304 & 1,152 & 616 & 3 & 3 & 2 & $3,681,756$ \\
\hline Air_3 & 9 & 358 & 1,607 & 760 & 631 & 170 & 3 & 8 & 4 & $3,389,642$ \\
\hline Air_4 & 13 & 87 & 1,599 & 36 & 1,316 & 175 & 3 & 8 & 4 & $3,389,642$ \\
\hline $\begin{array}{c}\mathrm{Non}_{-} \\
1\end{array}$ & 7 & 114 & 121 & 0 & 13 & 356 & 3 & 9 & 1 & $7,389,576$ \\
\hline $\begin{array}{c}\text { Fros }_{-} \\
1\end{array}$ & 27 & 207 & 558 & 9 & 109 & 1,010 & 3 & 5 & 2 & $1,373,188$ \\
\hline $\begin{array}{c}\text { Fros_ } \\
2 \\
\end{array}$ & 43 & 274 & 601 & 28 & 410 & 1,092 & 3 & 8 & 2 & $1,373,188$ \\
\hline Pin_1 & 47 & 256 & 191 & 9 & 90 & 180 & 3 & 1 & 2 & $1,074,963$ \\
\hline Pin_2 & 32 & 102 & 391 & 9 & 66 & 50 & 3 & 1 & 2 & 885,183 \\
\hline Pin_3 & 26 & 186 & 273 & 8 & 91 & 20 & 3 & 1 & 5 & $1,264,742$ \\
\hline Pin_4 & 42 & 102 & 899 & 2 & 10 & 443 & 2 & 2 & 5 & $1,454,522$ \\
\hline Pin_5 & 36 & 130 & 279 & 2 & 10 & 84 & 2 & 2 & 5 & $1,454,522$ \\
\hline Rol_ & 72 & 210 & 739 & 63 & 729 & 694 & 3 & 8 & 2 & $1,454,522$ \\
\hline
\end{tabular}




\begin{tabular}{|c|c|c|c|c|c|c|c|c|c|c|}
\hline $\mathbf{1}$ & & & & & & & & & & \\
\hline $\begin{array}{c}\text { Sca_ } \\
\mathbf{1}\end{array}$ & 26 & 129 & 336 & 2 & 12 & 39 & 3 & 2 & 2 & $3,355,219$ \\
\hline $\begin{array}{c}\text { Sca__ } \\
\mathbf{2}\end{array}$ & 16 & 123 & 315 & 0 & 10 & 32 & 3 & 2 & 2 & $3,355,219$ \\
\hline $\begin{array}{c}\text { Sca__ } \\
\mathbf{3}\end{array}$ & 12 & 86 & 437 & 1 & 11 & 77 & 3 & 2 & 2 & $3,355,219$ \\
\hline $\begin{array}{c}\text { Sca_- } \\
\mathbf{4}\end{array}$ & 12 & 71 & 227 & 1 & 4 & 10 & 3 & 7 & 2 & $3,131,470$ \\
\hline $\begin{array}{c}\text { Vol__ } \\
\mathbf{2}\end{array}$ & 34 & 34 & 482 & 113 & 148 & 203 & 3 & 8 & 1 & $5,936,932$ \\
\hline
\end{tabular}

Starting from the evaluations shown in Table 6, in order to apply the Choquet integral preference model, it is necessary to normalize the data set for each criterion. At a technical level, the raw values of each indicator for the alternative sites have thus been translated into the $0-1$ scale, where 0 encodes the less suitable value and 1 the most suitable value. If criterion $g_{i}$ has a decreasing direction of preference, that is, the lower is the evaluation of an alternative on $g_{i}$, the better is the alternative, the formula that has been used for the normalization is the following,

$$
\overline{g_{i}}(a)=\frac{\max _{i}-g_{i}(a)}{\max _{i}-\min _{i}}
$$

where $g_{i}(a)$ is the evaluation of $a$ on criterion $\mathrm{g}_{\mathrm{i}}, \overline{g_{i}}(a)$ the normalized value, and $\max _{i}$ and $\min _{i}$ the maximum and the minimum values used for the normalization.

Instead, if criterion $g_{i}$ has an increasing direction of preference, that is the higher is the evaluation of an alternative on $g_{i}$ the better is the alternative, the normalization formula (1) becomes:

$$
\overline{g_{i}}(a)=\frac{g_{i}(a)-\min _{i}}{\max _{i}-\min _{i}}
$$

The method that has been chosen in the present application is one of the most used among the different approaches available in the literature for the normalization of a set of sustainability indicator (Singh et al., 2012).

Let us observe that the normalized values obtained in this way will therefore be dependent on two different factors:

- the weights assigned to the permanent and transitory population so as to the distance from the considered site and used to obtain an aggregated evaluation on criterion $\mathrm{C} 1$,

- the max and min values chosen for each considered criterion.

In order to get recommendations as robust as possible, we performed a sensitivity analysis on the weights used for the aggregation of the evaluations on criterion $\mathrm{C} 1$ and on the min and max values chosen for the considered criteria.

With respect to the weights, we suppose that the permanent and transitory weights so as the weights referring to the distance from the site, are not fixed but can range within some intervals (see Table 7): 
Table 7 Interval weights considered for the definition of the equivalent population

\begin{tabular}{|c|c|c|c|c|}
\hline \multicolumn{2}{|c|}{ Type of population } & \multicolumn{3}{|c|}{ Distance from the site } \\
\hline Permanent & Transitory & $\mathbf{0 - 5 0 0}[\mathbf{m}]$ & $\mathbf{5 0 0 - 1 0 0 0}[\mathbf{m}]$ & $\mathbf{1 0 0 0 - 1 5 0 0}[\mathbf{m}]$ \\
\hline$[0.4,0.8]$ & {$[0.2,0.6]$} & {$[0.25,0.75]$} & {$[0.15,0.45]$} & {$[0.1,0.3]$} \\
\hline
\end{tabular}

Obviously, $\mathrm{w}_{\text {Permanent }}+\mathrm{w}_{\text {Transitory }}=1$ and $\mathrm{w}_{0-500}+\mathrm{w}_{500-1000}+\mathrm{w}_{1000-1500}=1$.

With respect to the max and min values used for the normalizations, let us observe that they do not have necessarily correspondence to the highest and lowest possible values of that criterion in absolute terms. Besides the selection of the bounds is not without consequences because this selection will influence the values obtained by means of the normalization.

For this reason, we decided to perform a sensitivity analysis also on the min and max values deciding to take into account three different min values $\left(\min ^{1}{ }_{\mathrm{i}}, \min ^{2}{ }_{\mathrm{i}}\right.$ and $\left.\min _{\mathrm{i}}{ }_{\mathrm{i}}\right)$ and three different $\max$ values $\left(\max ^{1}{ }_{\mathrm{i}}, \max ^{2}{ }_{\mathrm{i}}\right.$ and $\max ^{3}{ }_{\mathrm{i}}$ ) for each considered criterion $i$. In particular, the min and $\max$ values chosen for criteria C2-C4 are shown in Table 8.

Table 8 Min and Max values chosen for the normalization

\begin{tabular}{|l|c|c|c|c|}
\hline & C2 & C3 & C4 & C5 \\
\hline $\min ^{\mathbf{1}}{ }_{\mathbf{i}}$ & 1 & 0 & 1 & 480,037 \\
\hline $\mathbf{m i n}_{\mathbf{i}}^{\mathbf{2}}$ & 1.5 & 0.5 & 1.5 & 885,183 \\
\hline $\mathbf{m i n}_{\mathbf{i}}^{\mathbf{3}}$ & 2 & 1 & 2 & $1,074,963$ \\
\hline $\mathbf{m a x}_{\mathbf{i}}^{\mathbf{i}}$ & 4 & 9 & 5 & $5,936,932$ \\
\hline $\max _{\mathbf{i}}^{\mathbf{2}}$ & 4.5 & 9.5 & 5.5 & $6,573,754$ \\
\hline $\max _{\mathbf{i}}^{\mathbf{3}}$ & 5 & 10 & 6 & $7,389,576$ \\
\hline
\end{tabular}

While for criteria C2-C5 we have been able to define, a priori, three different min and max values, for criterion $\mathrm{C} 1$ it was not possible because the values on this criterion are not fixed but they depend on the weights chosen in order to aggregate the six considered subcriteria.

For this reason, with respect to criterion $\mathrm{C} 1$ the procedure will be the following:

- We sample a set of weights ( $\left.\mathrm{W}_{\text {Permanent }}, \mathrm{W}_{\text {Transitory, }}, \mathrm{W}_{0-500}, \mathrm{~W}_{500-1000}, \mathrm{~W}_{1000-1500}\right)$ from the intervals considered on Table 7 satisfying the two normalization constraints introduced above,

- Obtained the aggregated values on this criterion by means of the sampled weights, we consider as "possible" minima the last value, the third from last value and the fifth from last value and as "possible" maxima the first value, the third value and the fifth value.

For example, by aggregating the evaluations on criterion $\mathrm{C} 1$ using the weights considered in the original case study (and shown in Table 3), it is straightforward to observe that the aggregated evaluations on this criterion are those shown in Table 9. 
Table 9 Aggregated evaluations of all alternatives on criterion C1, using the weights considered in the original case study among those obtained.

\begin{tabular}{|c|c|c|c|c|c|}
\hline SITE & Equiv.pop. & SITE & Equiv.pop. & SITE & Equiv.pop. \\
\hline Air_A & 357.02 & Non_A & 67.36 & Fros_1 & 208 \\
\hline Air_B & 657.36 & Osa_A & 192.84 & Fros_2 & 276.5 \\
\hline Bri_A & 302.52 & Pin_A & 99.2 & Pin_1 & 110.1 \\
\hline Bur_A & 156.16 & Pin_B & 265.24 & Pin_2 & 88.6 \\
\hline Bur_B & 99.84 & Pis_A & 293.52 & Pin_3 & 88.16 \\
\hline Caf_A & 286.4 & Ssp_A & 669.72 & Pin_4 & 175.88 \\
\hline Cav_A & 72.88 & Vig_A & 43.72 & Pin_5 & 76 \\
\hline Crc_A & 52.64 & Vil_A & 76.8 & Rol_1 & 303.68 \\
\hline Cum_A & 323.24 & Vol_A & 186.04 & Sca_1 & 76.3 \\
\hline Cum_B & 62.32 & Air_2 & 658.66 & Sca_2 & 68.5 \\
\hline Frs_A & 63.3 & Air_3 & 501.3 & Sca_3 & 79.2 \\
\hline Frs_B & 77.54 & Air_4 & 390.56 & Sca_4 & 45.1 \\
\hline Mac_A & 211.66 & Non_1 & 67.18 & Vol_2 & 130.76 \\
\hline
\end{tabular}

In this case, the possible minima will be 43.72 (last value), 52.64 (third from last value) and 63.3 (fifth from last value) while the possible maxima will be 390.56 (fifth value), 657.36 (third value) and 669.72 (first value). As a consequence, if in that particular iteration, we had to take the first minimum value, then the min used in the normalization formula (1) will be 43.72. Analogously, if in the particular iteration, we had to take into account the second maximum, then the max in the normalization formula (1) will be 657.36.

Considering at each time a different combination of the three min and three max values for the five criteria, we will perform $3^{10}$ different simulations and, consequently, $3^{10}$ different normalizations of the considered data.

For example, by using the original weights considered in the real case study and shown in Table 3 , and considering the first $\min \left(\min ^{1}{ }_{\mathrm{i}}\right)$ for each criterion $(43.72,1,0,1,480037)$ and the third $\max$ $\left(\max ^{3}\right)$ for each criterion $(669.72,5,10,6,7389576)$ we obtain the normalized values shown in Table 10. 
Table 10 Normalized values considering the first min and the third maximum for each of the five criteria

\begin{tabular}{|c|c|c|c|c|c|}
\hline SITES & Population (C1) & Vulnerability (C2) & Agricultural value $(\mathrm{C} 3)$ & $\begin{array}{l}\text { Interference } \\
\text { with traffic } \\
\text { (C4) }\end{array}$ & $\begin{array}{l}\text { Operating } \\
\text { costs }(\mathrm{C} 5)\end{array}$ \\
\hline Air_A $\left(\mathbf{A}_{1}\right)$ & 0.4995 & 0.5 & 0.7777 & 0.8 & 0.5241 \\
\hline Air_B $\left(\mathbf{A}_{2}\right)$ & 0.0197 & 0.5 & 0.4444 & 0.8 & 0.5539 \\
\hline Bri_A (A $\left.\mathbf{A}_{3}\right)$ & 0.5865 & $\mathbf{0}$ & 0.2222 & 0.8 & 0.7530 \\
\hline Bur_A $\left(\mathbf{A}_{4}\right)$ & 0.8203 & 0.5 & $\mathbf{0}$ & 0.8 & 0.6549 \\
\hline Bur_B $\left(\mathbf{A}_{5}\right)$ & 0.9103 & 0.5 & 0.2222 & 0.8 & 0.7726 \\
\hline Caf_A $\left(A_{6}\right)$ & 0.6123 & 0.5 & $\mathbf{0 . 3 3 3 3}$ & 0.6 & 0.3198 \\
\hline Cav_A $\left(\mathbf{A}_{7}\right)$ & 0.9534 & $\mathbf{0}$ & 0.8888 & $\mathbf{0}$ & 0.2451 \\
\hline Crc_A $\left(\mathbf{A}_{8}\right)$ & 0.9857 & 0.5 & 0.6666 & 0.8 & 0.6162 \\
\hline Cum_A (A, & $\mathbf{0 . 5 5 3 4}$ & 1 & 0.7777 & 0.8 & 0.6667 \\
\hline Cum_B $\left(\mathbf{A}_{10}\right)$ & 0.9702 & 0.5 & 0.7777 & 0.4 & 0.5041 \\
\hline Frs_A $\left(\mathbf{A}_{11}\right)$ & 0.9687 & 0.5 & $\mathbf{1}$ & 0.8 & 0.6561 \\
\hline Frs_B $\left(\mathbf{A}_{12}\right)$ & 0.9459 & 0.5 & 0.8888 & 0.8 & 0.6627 \\
\hline Mac_A $\left(A_{13}\right)$ & 0.7317 & $\mathbf{0}$ & 0.4444 & 0.8 & 0.6470 \\
\hline Non_A $\left(A_{14}\right)$ & 0.9622 & 0.5 & 0.77778 & 0.4 & 0.0508 \\
\hline Osa_A $\left(\mathbf{A}_{15}\right)$ & 0.7617 & $\mathbf{0}$ & 0.1111 & 0.8 & 0.6980 \\
\hline Pin_A $\left(A_{16}\right)$ & 0.9113 & $\mathbf{0}$ & 0.4444 & 0.8 & 1 \\
\hline Pin_B $\left(\mathbf{A}_{17}\right)$ & 0.6461 & $\mathbf{0}$ & 0.2222 & 0.8 & 0.7647 \\
\hline Pis_A $\left(\mathbf{A}_{18}\right)$ & 0.6009 & 0.5 & 0.2222 & 1 & 0.6386 \\
\hline Ssp_A $\left(A_{19}\right)$ & $\mathbf{0}$ & $\mathbf{0}$ & 0.2222 & 0.8 & 0.8358 \\
\hline Vig_A $\left(A_{20}\right)$ & 1 & $\mathbf{0}$ & 0.4444 & 0.6 & 0.3273 \\
\hline Vil_A $\left(\mathbf{A}_{21}\right)$ & 0.9471 & $\mathbf{0}$ & 0.7777 & $\mathbf{0}$ & 0.1180 \\
\hline Vol_A (A $\left.\mathbf{A}_{22}\right)$ & 0.7726 & 0.5 & 0.2222 & 1 & 0.1454 \\
\hline Air_2 $\left(A_{23}\right)$ & 0.0176 & 0.5 & 0.2222 & 0.8 & 0.5366 \\
\hline Air_3 $\left(A_{24}\right)$ & 0.2690 & 0.5 & 0.7777 & 0.4 & 0.5789 \\
\hline Air_4 $\left(A_{25}\right)$ & 0.4459 & 0.5 & 0.7777 & 0.4 & 0.57890 \\
\hline Non_1 $\left(A_{26}\right)$ & 0.9625 & 0.5 & 0.8888 & 1 & $\mathbf{0}$ \\
\hline Fros_1 $\left(A_{27}\right)$ & 0.7375 & 0.5 & 0.4444 & 0.8 & 0.8707 \\
\hline Fros_2 $\left(\mathrm{A}_{28}\right)$ & 0.6281 & 0.5 & 0.7777 & 0.8 & 0.8707 \\
\hline Pin_1 $\left(A_{29}\right)$ & 0.8939 & 0.5 & $\mathbf{0}$ & 0.8 & 0.9138 \\
\hline Pin_2 $\left(A_{30}\right)$ & 0.9283 & 0.5 & $\mathbf{0}$ & 0.8 & 0.9413 \\
\hline Pin_3 $\left(A_{31}\right)$ & 0.9290 & 0.5 & $\mathbf{0}$ & 0.2 & 0.8864 \\
\hline Pin_4 $\left(A_{32}\right)$ & 0.7888 & 1 & 0.1111 & 0.2 & 0.8589 \\
\hline Pin_5 $\left(A_{33}\right)$ & 0.9484 & 1 & 0.1111 & 0.2 & 0.8589 \\
\hline Rol_1 ( $\left(\mathbf{A}_{34}\right)$ & 0.5847 & 0.5 & 0.7777 & 0.8 & 0.8589 \\
\hline Sca_1 (A $\left.A_{35}\right)$ & 0.9479 & 0.5 & 0.1111 & 0.8 & 0.5838 \\
\hline Sca_2 $\left(A_{36}\right)$ & 0.9604 & 0.5 & 0.1111 & 0.8 & 0.5838 \\
\hline Sca_3 (A $\left.\mathbf{A}_{37}\right)$ & 0.9433 & 0.5 & 0.1111 & 0.8 & 0.5838 \\
\hline Sca_4 $\left(A_{38}\right)$ & 0.9977 & 0.5 & 0.6666 & 0.8 & 0.6162 \\
\hline Vol_2 (A $\left.\mathbf{A}_{39}\right)$ & 0.8609 & 0.5 & 0.7777 & 1 & 0.2102 \\
\hline
\end{tabular}


Obviously, for each min and max choice, we get a different normalization Table and, consequently, the Choquet integral preference model will provide, in general, different rankings of the considered sites.

In order to apply the Choquet integral preference model by using the indirect preference information we considered the following subset of reference alternatives $A^{R}=$ (Frs_A, Sca_4, Crc_A, Pin_3, Bur_B, Frs_B), and , by simulating the decision making process, the panel of experts was able to provide the following preference information (among parenthesis we provided the constraints used to translate the corresponding preference information by using the Choquet integral preference model):

1. $\quad$ Sca_4 is preferred to Bur_B $\left(\mathrm{C}_{\mu}\left(\mathrm{Sca} \_4\right)>\mathrm{C}_{\mu}\left(\mathrm{Bur} \_\mathrm{B}\right)\right)$;

2. $\quad$ Frs_A is preferred to Bur_B more than Sca_4 is preferred to Crc_A $\left(C_{\mu}(\right.$ Frs_A $)-C_{\mu}($ Bur_B $)>C_{\mu}($ Sca_4 $\left.)-C_{\mu}\left(C r c \_A\right)\right)$;

3. Population is more important than interference with traffic $(\varphi(\{1\})>\varphi(\{4\}))$;

4. Operational costs are more important than agricultural value $(\varphi(\{5\})>\varphi(\{3\}))$;

5. There is a negative interaction between criteria "agricultural value" and "interference with traffic" $(\varphi(\{3,4\})<0)$;

6. There is a positive interaction between criteria "vulnerability" and "population" ( $\varphi$ $(\{1,2\})>0)$;

7. Sca 4 is better than Pin_3 $\left(\mathrm{C}_{\mu}\left(\mathrm{Sca} \_4\right)>\mathrm{C}_{\mu}\left(\mathrm{Pin} \_3\right)\right)$;

8. Sca_4 is preferred to Bur_B more than Frs_A is preferred to Frs_B

$\left(C_{\mu}(\right.$ Sca_4 $)-C_{\mu}($ Bur_B $)>C_{\mu}($ Frs_A $)-C_{\mu}($ Frs_B $\left.)\right)$;

9. Vulnerability is more important than agricultural value $(\varphi(\{2\})>\varphi(\{3\}))$;

10. Population is preferred to interference with traffic more than vulnerability is preferred to agricultural value $(\varphi(\{1\})-\varphi(\{4\})>\varphi(\{2\})-\varphi(\{3\}))$;

11. There is a positive interaction between criteria "agricultural value" and "population" $(\varphi$ $(\{1,3\})>0)$.

The aforementioned interactions can be explained as follows:

1. Negative interaction between "agricultural value" and "interference with traffic". In fact, a site that is characterized by an high presence of road infrastructure in the surrounding area has normally a low agricultural value (because of the negative impacts caused by the presence of pollutant emissions produced by the vehicles on the roads, consumption of soil, etc.). Consequently, the importance of this couple of criteria is smaller than the sum of the importance of the two criteria considered separately.

2. Positive interaction between vulnerability and population. In fact, a site characterized by a low vulnerability is normally highly populated (because it is easy and cheap to construct houses, roads and other services if the site is not affected by a vulnerable underground aquifer). So a site characterized by a low vulnerability and a small presence of population is very well appreciated. In this case, the importance of this couple of criteria is greater than the sum of the importance of the two criteria considered separately. 
At each iteration, in order to check if the Choquet integral is able to restore the preferences provided by the DM, one has to solve the following linear program (Marichal \& Roubens 2000):

$$
\begin{aligned}
& \max \varepsilon=\varepsilon^{*} \\
& \text { s.t. } \mathrm{E}^{\mathrm{AR} .}
\end{aligned}
$$

If $\mathrm{E}^{\mathrm{AR}}$ is feasible and $\varepsilon^{*}>0$ then there exists at least one capacity for which the Choquet integral is able to restore the preferences of the DM. Vice versa, there is no capacity for which the Choquet integral preference model is able to restore the preferences provided by the DM.

Let us observe, that in the procedure shown above, the presence of a capacity for which the Choquet integral is compatible with the preferences of the DM is strongly dependent from the choice of the min and max values because, as we already observed, this choice will influence the considered normalization. As a consequence, for some particular choices of min and max values the Choquet integral preference model was not able to restore the preferences of the DM. In our application, the DM's preferences have been restored in all the iterations $\left(59,049=3^{10}\right)$. As a consequence, at each iteration we applied the Choquet integral preference model by considering the capacity obtained by solving the LP problem (2) and computing the values of all sites. Because the application of the Choquet integral preference model provides a complete ranking of the considered sites, we stored the obtained rankings.

At the end of all iterations, we computed the Rank Acceptability Indices (RAI) that are indices typical of the family of the Stochastic Multicriteria Acceptability Analysis (SMAA) methods (Lahdelma et al. 1998; see Tervonen \& Figueira, 2008 for a survey on SMAA methods).

The rank acceptability index $b_{l}{ }^{k}$ gives the frequency that site $A_{\mathrm{k}}$ has rank $l$ in the different final rankings obtained. In this particular case, we computed two variants of the rank acceptability indices that we shall call downward and upward cumulative rank acceptability indices and that will be denoted by $b_{\leq l}^{k}$ and $b_{\geq l}^{k}$. By $b_{\leq l}^{k}$ we shall indicate the frequency that alternative $A_{\mathrm{k}}$ will get ranks no greater than $l$ while by $b^{k} \geq l$ we shall indicate the frequency that alternative $A_{\mathrm{k}}$ will get ranks no lower than $l$. We can easily get that

$$
b_{\leq l}^{k}=\sum_{s=1}^{l} b_{s}^{k} \quad \text { and } \quad b_{\geq l}^{k}=\sum_{s=l}^{n} b_{s}^{k}
$$

where $n$ is the number of considered alternatives. In the Appendix A, we reported two different Tables related to the cumulative rank acceptability indices. In Table13, for each considered site $A_{\mathrm{k}}$ we reported the downward cumulative rank acceptability indices $b_{\leq l}^{k}, l=1, \ldots, 5$, while in Table 14 we reported for each site $A_{\mathrm{k}}$ the upward cumulative rank acceptability indices $b_{\geq l}^{k}, l=35, \ldots, 39$.

Looking at Table 13, we can observe that site $A_{11}$ can be considered as the best site because $b_{\leq 1}^{11}=86.29 \%$ and, therefore, $A_{11}$ is the site being most frequently in the first position. Besides, we can observe that $b^{11}=99.26 \%$ meaning that the rank of $A_{11}$ is really stable because $A_{11}$ almost always is in the first five positions of the ranking.

From Table 13 it is also possible to notice that the site $\mathrm{A}_{12}$ does not recur very often in the first position $\left(b^{12} \leq 1=2.09 \%\right)$. Following the same reasoning we can affirm that the site $\mathrm{A}_{16}$ never appears in the first position $\left(b^{16} \leq 1=0 \%\right)$. 
Looking at the upward cumulative rank acceptability indices in Table 14 one can observe that even if $A_{6}, A_{15}, A_{19}$ and $A_{23}$ can be last in the ranking with similar frequencies $\left(b^{6}{ }_{39}=23.02 \%\right.$, $b^{15}{ }_{39}=26.65 \%, b^{19}{ }_{39}=23.73 \%$ and $\left.b^{23}{ }_{39}=24.81 \%\right), A_{15}$ and $A_{23}$ can be considered the worst sites because they are in the last five positions in the ranking with frequencies of $b^{15} \geq 35=81.42 \%$ and $b^{23} \geq 35=82.63 \%$, respectively.

Even if this information is very meaningful, in general the DM would like to have one ranking of all the considered sites. For this reason, we decided to apply the NAROR to get the necessary and possible preference relations introduced in the previous sections and, consequently, computing the most representative value function (MRVF) taking into account the results of the NAROR and giving a total order of all the sites at hand.

In order to get a unique scale to which apply the NAROR, we considered the normalization values providing the greatest value of $\varepsilon^{*}$ that is the normalization values most discriminant with respect to the preferences of the DM. By computing the MRVF, we get the final ranking shown in Table 11.

Table 11 Ranking of the sites obtained by applying the MRVF.

\begin{tabular}{|c|c|c|c|c|c|}
\hline Site & Choquet integral value & Site & Choquet integral value & Site & Choquet integral value \\
\hline $\mathbf{A}_{11}$ & $\mathbf{0 . 9 6 6 2}$ & $\mathbf{A}_{30}$ & $\mathbf{0 . 8 5 0 8}$ & $\mathbf{A}_{17}$ & $\mathbf{0 . 6 5 3 4}$ \\
$\mathbf{A}_{38}$ & $\mathbf{0 . 9 5 0 3}$ & $\mathbf{A}_{35}$ & $\mathbf{0 . 8 3 2 8}$ & $\mathbf{A}_{3}$ & $\mathbf{0 . 6 5 0 2}$ \\
$\mathbf{A}_{12}$ & $\mathbf{0 . 9 4 6 5}$ & $\mathbf{A}_{29}$ & $\mathbf{0 . 8 3 1 9}$ & $\mathbf{A}_{15}$ & $\mathbf{0 . 6 3 2 0}$ \\
$\mathbf{A}_{26}$ & $\mathbf{0 . 9 4 2 4}$ & $\mathbf{A}_{31}$ & $\mathbf{0 . 8 1 2 1}$ & $\mathbf{A}_{13}$ & $\mathbf{0 . 6 1 9 0}$ \\
$\mathbf{A}_{8}$ & $\mathbf{0 . 9 3 4 4}$ & $\mathbf{A}_{37}$ & $\mathbf{0 . 8 1 1 4}$ & $\mathbf{A}_{18}$ & $\mathbf{0 . 6 1 0 7}$ \\
$\mathbf{A}_{10}$ & $\mathbf{0 . 9 3 0 6}$ & $\mathbf{A}_{39}$ & $\mathbf{0 . 7 9 5 5}$ & $\mathbf{A}_{9}$ & $\mathbf{0 . 6 0 9 3}$ \\
$\mathbf{A}_{20}$ & $\mathbf{0 . 9 1 2 7}$ & $\mathbf{A}_{28}$ & $\mathbf{0 . 7 8 7 4}$ & $\mathbf{A}_{22}$ & $\mathbf{0 . 5 4 9 4}$ \\
$\mathbf{A}_{14}$ & $\mathbf{0 . 8 9 6 6}$ & $\mathbf{A}_{27}$ & $\mathbf{0 . 7 8 6 5}$ & $\mathbf{A}_{1}$ & $\mathbf{0 . 5 1 8 5}$ \\
$\mathbf{A}_{7}$ & $\mathbf{0 . 8 8 3 7}$ & $\mathbf{A}_{34}$ & $\mathbf{0 . 7 7 1 5}$ & $\mathbf{A}_{2}$ & $\mathbf{0 . 5 0 6 6}$ \\
$\mathbf{A}_{16}$ & $\mathbf{0 . 8 8 0 6}$ & $\mathbf{A}_{5}$ & $\mathbf{0 . 7 6 3 4}$ & $\mathbf{A}_{23}$ & $\mathbf{0 . 4 9 0 7}$ \\
$\mathbf{A}_{21}$ & $\mathbf{0 . 8 6 7 8}$ & $\mathbf{A}_{32}$ & $\mathbf{0 . 7 1 4 4}$ & $\mathbf{A}_{24}$ & $\mathbf{0 . 4 4 6 9}$ \\
$\mathbf{A}_{33}$ & $\mathbf{0 . 8 6 2 0}$ & $\mathbf{A}_{19}$ & $\mathbf{0 . 6 7 2 5}$ & $\mathbf{A}_{25}$ & $\mathbf{0 . 4 4 6 9}$ \\
$\mathbf{A}_{36}$ & $\mathbf{0 . 8 5 4 7}$ & $\mathbf{A}_{4}$ & $\mathbf{0 . 6 5 4 5}$ & $\mathbf{A}_{6}$ & $\mathbf{0 . 3 6 3 0}$ \\
\hline
\end{tabular}

Looking at the results shown in Table 11, we have the confirmation that site $A_{11}$ is the best among the 39 considered sites while $A_{6}$ is the worst one.

Since the first 10 sites in the considered ranking shown in Table 11 have values got by the Choquet integral preference model very close, we decided to show the DM the Table 12 representing the necessary preference relation for the 10 considered sites and the graph translating this preference relation. 
Table 12 Necessary preference relation obtained by applying the NAROR methodology. In the Table, value 1 in position $(k, l)$ means that site Ak is necessarily preferred to site Al while value 0 means that Ak is not necessarily preferred to Al.

\begin{tabular}{|c|cccccccccc|}
\hline$\succeq^{\mathbf{N}}$ & $\mathbf{A}_{\mathbf{7}}$ & $\mathbf{A}_{\mathbf{8}}$ & $\mathbf{A}_{\mathbf{1 0}}$ & $\mathbf{A}_{\mathbf{1 1}}$ & $\mathbf{A}_{\mathbf{1 2}}$ & $\mathbf{A}_{\mathbf{1 4}}$ & $\mathbf{A}_{\mathbf{1 6}}$ & $\mathbf{A}_{\mathbf{2 0}}$ & $\mathbf{A}_{\mathbf{2 6}}$ & $\mathbf{A}_{\mathbf{3 8}}$ \\
\hline $\mathbf{A}_{\mathbf{7}}$ & 1 & 0 & 0 & 0 & 0 & 0 & 0 & 0 & 0 & 0 \\
$\mathbf{A}_{\mathbf{8}}$ & 0 & 1 & 0 & 0 & 0 & 0 & 0 & 0 & 0 & 0 \\
$\mathbf{A}_{10}$ & 0 & 0 & 1 & 0 & 0 & 1 & 0 & 0 & 0 & 0 \\
$\mathbf{A}_{11}$ & 1 & 1 & 1 & 1 & 0 & 1 & 0 & 1 & 0 & 1 \\
$\mathbf{A}_{12}$ & 1 & 0 & 1 & 0 & 1 & 1 & 0 & 0 & 0 & 0 \\
$\mathbf{A}_{14}$ & 0 & 0 & 0 & 0 & 0 & 1 & 0 & 0 & 0 & 0 \\
$\mathbf{A}_{16}$ & 0 & 0 & 0 & 0 & 0 & 0 & 1 & 0 & 0 & 0 \\
$\mathbf{A}_{\mathbf{2 0}}$ & 0 & 0 & 0 & 0 & 0 & 0 & 0 & 1 & 0 & 0 \\
$\mathbf{A}_{\mathbf{2 6}}$ & 0 & 0 & 0 & 0 & 0 & 1 & 0 & 0 & 1 & 0 \\
$\mathbf{A}_{\mathbf{3 8}}$ & 0 & 1 & 0 & 0 & 0 & 0 & 0 & 1 & 0 & 1 \\
\hline
\end{tabular}

Figure 1 Graphical representation (Hasse diagram) of the necessary preference relation. An arrow is directed from $A_{k}$ to $A_{l}$ if $A_{k}$ is necessarily preferred to $A_{l}$. There are not arcs for necessary preferences that can be obtained by transitivity (e.g. there is not an arc from $A_{11}$ to $A_{14}$, because the necessary preference of $A_{11}$ over $A_{14}$ can be obtained from the necessary preference of $A_{11}$ over $A_{10}$ and of $A_{10}$ over $A_{14}$ ).

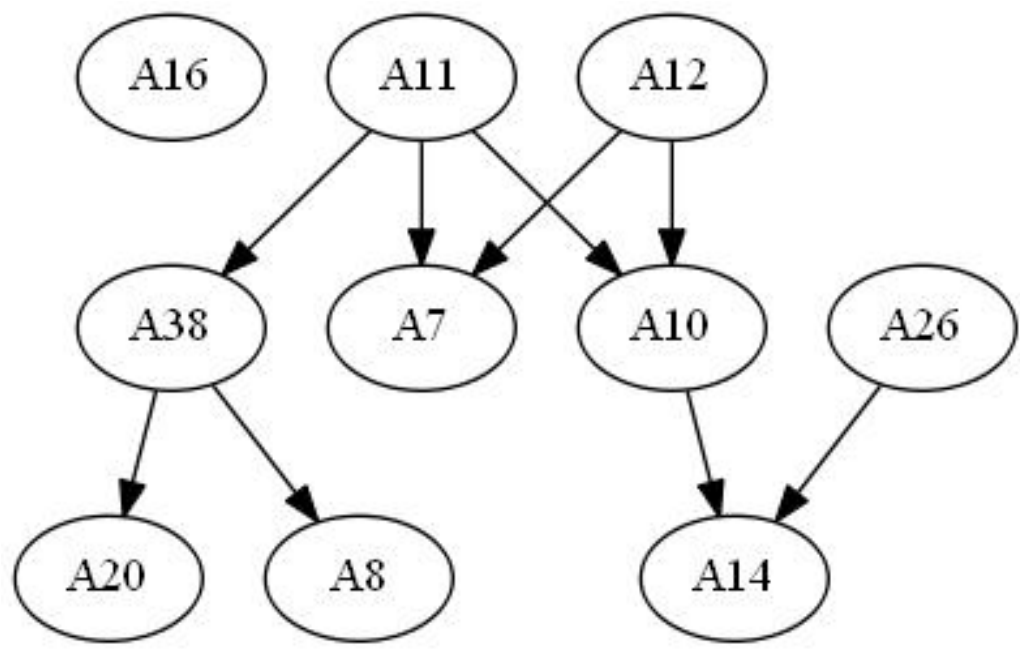

Looking at Figure 1, one can observe that site $\mathrm{A}_{11}$ is necessarily preferred to six out of the nine sites in the first ten positions and this could explain why it gets the highest value by applying the MRVF.

At this point, we think that the DM has enough solid arguments to choose site $A_{11}$ for siting the urban waste landfill. 


\section{Conclusions}

Governments are slowly realizing that inaction is simply not an option in territorial conflicts. Negotiation is just one among the tools that governments have at their disposal for facilitating infrastructure and undesirable facilities delivery; this tool requires a very careful application. In this sense, Multiple Criteria Decision Aiding (MCDA) methodology allows the theme of participation to be integrated in the decision-making process: the methodology permits to consider not only numerical data, statistics, etc., but also preferences and feelings of the Decision Maker (DM); it may contribute to the construction and review of alternatives; it takes into account the views of different actors, even with heterogeneous languages.

But in the territorial conflicts the subject of dispute is far from unique. The dispute relates, often simultaneously, on several aspects: the nature of the general or particular aspects, the existence of occult interests, the redefinition of costs and benefits, the risk assessment, the decisional power of the communities involved and their identity, the possibility of following alternative paths of development. This is why the outcome of these conflicts appears so problematic and uncertain. One negotiating solution concerning the actions for mitigating and compensating the estimated impacts of the project can be easily defeated by a new discussion about territorial identity, local decisional power or the opportunities of constructing the proposed project (Bobbio, 2011).

As a consequence, in recent years, a new model of decision making is emerging in Europe. In fact, the consensus is no more sought, it is now nearly impossible to be achieved, especially in the field of large-scale infrastructures and undesirable facilities location. The decisions have more and more a geopolitical nature and therefore decision support tools such as MCDA are more and more often used for explaining and justifying the decision. This justification must be produced in front of a jury, in a real contradictory legal system or, more in general, in the public opinion debate.

Precisely in this context, the paper proposes the application of a multicriteria methodology, namely the Non Additive Robust Ordinal Regression (NAROR). NAROR permits to represent a quite complex aspect of the decision problem we are considering such as interaction between criteria, with a preference model enough manageable and controllable by the DM, and also by the analyst, by maintaining not too heavy and easily understandable the preference information required by the model. NAROR permits also to deal with robustness concerns by distinguishing between necessary and possible preferences, that hold for any set or at least one set, respectively, of preference parameters compatible with the DM's preferences. Let us remark that the paper represents the first attempt to simulate the application of the NAROR to a real world decision making problem, even if not already with real DMs, but with a panel of experts simulating the decisional process. The considered case study consists of choosing the most suitable location for a Municipal Solid Waste landfill, which has to be constructed in the Province of Torino (Italy).

The alternatives taken in consideration are 39 sites that have been identified as potentially suitable for the location of the landfill. The 39 sites have been evaluated on the basis of the following five criteria: population, vulnerability, agricultural value, interference with traffic and operating costs. The case study considered is characterized by two main aspects: too many alternatives under evaluation and considered criteria which are interacting either positively or negatively. 
The selection of the NAROR theory for addressing the decision problem is strictly related to the nature of the case under investigation. Starting from the aforementioned complexity related to the high number of alternatives and to the existence of criteria interactions, we choose the NAROR methodology because we considered the method as potentially suitable for dealing with the specific characteristics of the considered problem.

The choice to apply the NAROR is directly linked to the fact that it can handle a very large number of alternatives with respect to the number of preferences required, as evidenced by the case study here described. The simulation that has been performed in the present application highlights that it is possible, starting from a very limited number of information required from the DM, to reach a very clear and readable result, even if the mathematical and logical procedure is rich and articulated.

After the development of the application we found that the proposed model is suitable to represent the real problems of a territorial system and the complexity of the decision under examination, leading towards an integrated assessment. This application represents a test case for studying the usefulness of the considered method in the evaluation of the interaction between criteria, which is a more and more an interesting research issue in MCDA, in general, and in sustainability assessments, in particular.

Indeed, we believe, that this paper proposes the first application in which ROR, SMAA, Choquet integral, Most Representative Value Function, robustness analysis of the normalization of criteria are used in a coordinated way obtaining results which seem very interesting for formulating proper recommendations in complex decision making problems. Thus, we hope that the procedure presented in this paper can become a prototype for future real world applications.

Let us observe also that from the methodological point of view, our paper introduces the downward and upward cumulative rank acceptability indices that, to the best of our knowledge, have not been considered before in literature. We think that these indices are really meaningful in all SMAA methodologies because they permit to interpret in a proper way its final outputs.

We envisage some possible directions of future research:

- Consideration of a plurality of DMs, with different preference information. In this case, a consensus among the DMs has to be reached (for an application of Robust Ordinal Regression (ROR) to group decision making problems see, for example, Greco et al. 2012);

- Consideration of a hierarchal structure of criteria within the Multiple Criteria Hierarchy Process (Corrente et. al 2012) that has been applied to the Choquet integral preference model in Angilella et al. 2013;

- Application of all ROR extensions, such as SMAA applied to ROR (see, for example, Kadziński \& Tervonen 2013);

- Application of the procedure proposed in Angilella et al. 2004 and further developed in Angilella et al. 2014 to build common scales based on the DM's preferences instead of normalizing the performances of the alternatives on the considered criteria;

- Integration of the MCDA model with Geographic Information Systems (GIS) in order to develop a Multicriteria Spatial Decision Support System (Malczewski 1999; Ferretti and Pomarico 2013). 



\section{Appendix A: Rank acceptability indices}

Tabel 13 Cumulative rank acceptability indices $b_{\leq l}^{k}$ for all 39 considered sites and for $l=1, \ldots, 5$.

\begin{tabular}{|c|c|c|c|c|c|c|c|c|c|c|c|c|c|c|c|c|c|c|c|}
\hline \multicolumn{2}{|c|}{$A_{1}$} & \multicolumn{2}{|c|}{$A_{2}$} & \multicolumn{2}{|c|}{$A_{3}$} & \multicolumn{2}{|c|}{$A_{4}$} & \multicolumn{2}{|c|}{$A_{5}$} & \multicolumn{2}{|c|}{$A_{6}$} & \multicolumn{2}{|c|}{$A_{7}$} & \multicolumn{2}{|c|}{$A_{8}$} & \multicolumn{2}{|c|}{$A_{9}$} & \multicolumn{2}{|c|}{$A_{10}$} \\
\hline$b_{\leq 1}$ & 0 & $b_{\leq 1}$ & 0 & $b_{\leq 1}$ & 0 & $b_{\leq 1}$ & 0 & $b_{\leq 1}$ & 0 & $b_{\leq 1}$ & 0 & $b_{\leq 1}$ & 0 & $b_{\leq 1}$ & 0 & $b_{\leq 1}$ & 2.70 & $b_{\leq 1}$ & 0.91 \\
\hline$b_{\leq 2}$ & 0 & $b_{\leq 2}$ & 0 & $b_{\leq 2}$ & 0 & $b_{\leq 2}$ & 0 & $b_{\leq 2}$ & 0 & $b_{\leq 2}$ & 0 & $b_{\leq 2}$ & 0 & $b_{\leq 2}$ & 4.54 & $b_{\leq 2}$ & 5.86 & $b_{\leq 2}$ & 2.54 \\
\hline$b_{\leq 3}$ & 0 & $b_{\leq 3}$ & 0 & $b_{\leq 3}$ & 0 & $b_{\leq 3}$ & 0 & $b_{\leq 3}$ & 0 & $b_{\leq 3}$ & 0 & $b_{\leq 3}$ & 0 & $b_{\leq 3}$ & 9.62 & $b_{\leq 3}$ & 14.25 & $b_{\leq 3}$ & 21.45 \\
\hline$b_{\leq 4}$ & 0 & $b_{\leq 4}$ & 0 & $b_{\leq 4}$ & 0 & $b_{\leq 4}$ & 0 & $b_{\leq 4}$ & 0 & $b_{\leq 4}$ & 0 & $b_{\leq 4}$ & 0 & $b_{\leq 4}$ & 42.31 & $b_{\leq 4}$ & 18.62 & $b_{\leq 4}$ & 36.73 \\
\hline$b_{\leq 5}$ & 0 & $b_{\leq 5}$ & 0 & $\boldsymbol{b}_{\leq 5}$ & 0 & $b_{\leq 5}$ & 0 & $b_{\leq 5}$ & 0 & $\boldsymbol{b}_{\leq 5}$ & 0 & $b_{\leq 5}$ & 0 & $\boldsymbol{b}_{\leq 5}$ & 69.74 & $b_{\leq 5}$ & 22.33 & $b_{\leq 5}$ & 62.09 \\
\hline
\end{tabular}

\begin{tabular}{|c|c|c|c|c|c|c|c|c|c|c|c|c|c|c|c|c|c|c|c|}
\hline \multicolumn{2}{|c|}{$A_{11}$} & \multicolumn{2}{|c|}{$A_{12}$} & \multicolumn{2}{|c|}{$A_{13}$} & \multicolumn{2}{|c|}{$A_{14}$} & \multicolumn{2}{|c|}{$A_{15}$} & \multicolumn{2}{|c|}{$A_{16}$} & & & \multicolumn{2}{|c|}{$A_{18}$} & \multicolumn{2}{|c|}{$A_{19}$} & \multicolumn{2}{|c|}{$A_{20}$} \\
\hline$b_{\leq 1}$ & 86.29 & $b_{\leq 1}$ & 2.09 & $b_{\leq 1}$ & 0 & $b_{\leq 1}$ & 0 & $b_{\leq 1}$ & 0 & $b_{\leq 1}$ & 0 & $b_{\leq 1}$ & 0 & $b_{\leq 1}$ & 0 & $b_{\leq 1}$ & 0 & $b_{\leq 1}$ & 0 \\
\hline$b_{\leq 2}$ & 93.34 & $b_{\leq 2}$ & 70.72 & $b_{\leq 2}$ & 0 & $b_{\leq 2}$ & 0.03 & $b_{\leq 2}$ & 0 & $b_{\leq 2}$ & 0.01 & $b_{\leq 2}$ & 0 & $b_{\leq 2}$ & 0 & $b_{\leq 2}$ & 0 & $b_{\leq 2}$ & 0 \\
\hline$b_{\leq 3}$ & 96.53 & $b_{\leq 3}$ & 85.20 & $b_{\leq 3}$ & 0 & $b_{\leq 3}$ & 0.24 & $b_{\leq 3}$ & 0 & $b_{\leq 3}$ & 0.01 & $b_{\leq 3}$ & 0 & $b_{\leq 3}$ & 0 & $b_{\leq 3}$ & 0 & $b_{\leq 3}$ & 0 \\
\hline$b_{\leq 4}$ & 98.58 & $b_{\leq 4}$ & 90.46 & $b_{\leq 4}$ & 0 & $b_{\leq 4}$ & 0.86 & $b_{\leq 4}$ & 0 & $b_{\leq 4}$ & 0.02 & $b_{\leq 4}$ & 0 & $b_{\leq 4}$ & 0 & $b_{\leq 4}$ & 0 & $b_{\leq 4}$ & 0 \\
\hline$b_{\leq 5}$ & 99.26 & $b_{\leq 5}$ & 94.90 & $b_{\leq 5}$ & 0 & $b_{\leq 5}$ & 4.59 & $b_{\leq 5}$ & 0 & $b_{\leq 5}$ & 0.04 & $b_{\leq 5}$ & 0 & $b_{\leq 5}$ & 0 & $b_{\leq 5}$ & 0 & $b_{\leq 5}$ & 0 \\
\hline
\end{tabular}

\begin{tabular}{|c|c|c|c|c|c|c|c|c|c|c|c|c|c|c|c|c|c|c|c|}
\hline \multicolumn{2}{|c|}{$A_{21}$} & \multicolumn{2}{|c|}{$A_{22}$} & \multicolumn{2}{|c|}{$A_{23}$} & \multicolumn{2}{|c|}{$A_{24}$} & \multicolumn{2}{|c|}{$A_{25}$} & \multicolumn{2}{|c|}{$A_{26}$} & \multicolumn{2}{|c|}{$A_{27}$} & \multicolumn{2}{|c|}{$A_{28}$} & \multicolumn{2}{|c|}{$A_{29}$} & \multicolumn{2}{|c|}{$A_{30}$} \\
\hline$b_{\leq 1}$ & 0 & $b_{\leq 1}$ & 0 & $b_{\leq 1}$ & 0 & $b_{\leq 1}$ & 0 & $b_{\leq 1}$ & 0 & $b_{\leq 1}$ & 2.71 & $b_{\leq 1}$ & 0 & $b_{\leq 1}$ & 0.01 & $b_{\leq 1}$ & 0 & $b_{\leq 1}$ & 0 \\
\hline$b_{\leq 2}$ & 0 & $b_{\leq 2}$ & 0 & $b_{\leq 2}$ & 0 & $b_{\leq 2}$ & 0 & $b_{\leq 2}$ & 0 & $b_{\leq 2}$ & 11.90 & $b_{\leq 2}$ & 0 & $b_{\leq 2}$ & 0.10 & $b_{\leq 2}$ & 0 & $b_{\leq 2}$ & 0 \\
\hline$b_{\leq 3}$ & 0 & $b_{\leq 3}$ & 0 & $b_{\leq 3}$ & 0 & $b_{\leq 3}$ & 0 & $b_{\leq 3}$ & 0 & $b_{\leq 3}$ & 16.48 & $b_{\leq 3}$ & 0 & $b_{\leq 3}$ & 8.76 & $b_{\leq 3}$ & 0 & $b_{\leq 3}$ & 0 \\
\hline$b_{\leq 4}$ & 0 & $b_{\leq 4}$ & 0 & $b_{\leq 4}$ & 0 & $b_{\leq 4}$ & 0 & $b_{\leq 4}$ & 0 & $b_{\leq 4}$ & 18.10 & $\boldsymbol{b}_{\leq 4}$ & 0 & $b_{\leq 4}$ & 12.93 & $b_{\leq 4}$ & 0 & $b_{\leq 4}$ & 0 \\
\hline$b_{\leq 5}$ & 0 & $b_{\leq 5}$ & 0 & $b_{\leq 5}$ & 0 & $\boldsymbol{b}_{\leq 5}$ & 0 & $b_{\leq 5}$ & 0 & $b_{\leq 5}$ & 19.70 & $\boldsymbol{b}_{\leq 5}$ & 0.02 & $b_{\leq 5}$ & 22.20 & $\boldsymbol{b}_{\leq 5}$ & 0 & $\boldsymbol{b}_{\leq 5}$ & 0 \\
\hline
\end{tabular}




\begin{tabular}{|c|c|c|c|c|c|c|c|c|c|c|c|c|c|c|c|c|c|}
\hline \multicolumn{2}{|c|}{$A_{31}$} & \multicolumn{2}{|c|}{$A_{32}$} & \multicolumn{2}{|c|}{$A_{33}$} & \multicolumn{2}{|c|}{$A_{34}$} & \multicolumn{2}{|c|}{$A_{35}$} & \multicolumn{2}{|c|}{$A_{36}$} & \multicolumn{2}{|c|}{$A_{37}$} & \multicolumn{2}{|c|}{$A_{38}$} & \multicolumn{2}{|c|}{$A_{39}$} \\
\hline$b_{\leq 1}$ & 0 & $b_{\leq 1}$ & 0 & $b_{\leq 1}$ & 0.03 & $b_{\leq 1}$ & 0 & $b_{\leq 1}$ & 0 & $b_{\leq 1}$ & 0 & $b_{\leq 1}$ & 0 & $b_{\leq 1}$ & 5.23 & $b_{\leq 1}$ & 0 \\
\hline$b_{\leq 2}$ & 0 & $b_{\leq 2}$ & 0 & $b_{\leq 2}$ & 0.09 & $b_{\leq 2}$ & 0 & $b_{\leq 2}$ & 0 & $b_{\leq 2}$ & 0 & $b_{\leq 2}$ & 0 & $b_{\leq 2}$ & 10.82 & $b_{\leq 2}$ & 0 \\
\hline$b_{\leq 3}$ & 0 & $b_{\leq 3}$ & 0 & $b_{\leq 3}$ & 1.29 & $b_{\leq 3}$ & 0.01 & $b_{\leq 3}$ & 0 & $b_{\leq 3}$ & 0 & $b_{\leq 3}$ & 0 & $b_{\leq 3}$ & 46.10 & $b_{\leq 3}$ & 0 \\
\hline$b_{\leq 4}$ & 0 & $b_{\leq 4}$ & 0.16 & $b_{\leq 4}$ & 3.16 & $b_{\leq 4}$ & 3.86 & $b_{\leq 4}$ & 0 & $b_{\leq 4}$ & 0 & $b_{\leq 4}$ & 0 & $b_{\leq 4}$ & 74.16 & $b_{\leq 4}$ & 0.01 \\
\hline$b_{\leq 5}$ & 0 & $b_{\leq 5}$ & 0.54 & $b_{\leq 5}$ & 5.79 & $b_{\leq 5}$ & 6.32 & $b_{\leq 5}$ & 0 & $b_{\leq 5}$ & 0 & $b_{\leq 5}$ & 0 & $b_{\leq 5}$ & 92.36 & $b_{\leq 5}$ & 0.04 \\
\hline
\end{tabular}

Table 14 Cumulative rank acceptability indices $b_{\geq 1}^{k}$ for all 39 considered sites and for $l=35, \ldots, 39$.

\begin{tabular}{|c|c|c|c|c|c|c|c|c|c|c|c|c|c|c|c|c|c|c|c|}
\hline \multicolumn{2}{|r|}{$A_{1}$} & \multicolumn{2}{|r|}{$A_{2}$} & \multicolumn{2}{|c|}{$A_{3}$} & \multicolumn{2}{|c|}{$A_{4}$} & \multicolumn{2}{|c|}{$A_{5}$} & \multicolumn{2}{|c|}{$A_{6}$} & \multicolumn{2}{|c|}{$A_{7}$} & \multicolumn{2}{|c|}{$A_{8}$} & \multicolumn{2}{|c|}{$A_{9}$} & \multicolumn{2}{|c|}{$A_{10}$} \\
\hline$b_{\geq 35}$ & 11.62 & $b_{\geq 35}$ & 50.91 & $b_{\geq 35}$ & 61.59 & $b_{\geq 35}$ & 0.02 & $b_{\geq 35}$ & 0 & $b_{\geq 35}$ & 38.17 & $b_{\geq 35}$ & 0.01 & $b_{\geq 35}$ & 0 & $b_{\geq 35}$ & 0 & $b_{\geq 35}$ & 0 \\
\hline$b_{\geq 36}$ & 8.83 & $b_{\geq 36}$ & 41.01 & $b_{\geq 36}$ & 47.31 & $b_{\geq 36}$ & 0.01 & $b_{\geq 36}$ & 0 & $b_{\geq 36}$ & 32.96 & $b_{\geq 36}$ & 0.01 & $b_{\geq 36}$ & 0 & $b_{\geq 36}$ & 0 & $b_{\geq 36}$ & 0 \\
\hline$b_{\geq 37}$ & 1.73 & $b_{\geq 37}$ & 28.57 & $b_{\geq 37}$ & 32.51 & $b_{\geq 37}$ & 0 & $b_{\geq 37}$ & 0 & $b_{\geq 37}$ & 29.10 & $b_{\geq 37}$ & 0 & $b_{\geq 37}$ & 0 & $b_{\geq 37}$ & 0 & $b_{\geq 37}$ & 0 \\
\hline$b_{\geq 38}$ & 0.02 & $b_{\geq 38}$ & 11.83 & $b_{\geq 38}$ & 8.40 & $b_{\geq 38}$ & 0 & $b_{\geq 38}$ & 0 & $b_{\geq 38}$ & 26.19 & $b_{\geq 38}$ & 0 & $b_{\geq 38}$ & 0 & $b_{\geq 38}$ & 0 & $b_{\geq 38}$ & 0 \\
\hline$b_{\geq 39}$ & 0 & $b_{\geq 39}$ & 0.57 & $b_{\geq 39}$ & 0.11 & $b_{\geq 39}$ & 0 & $b_{\geq 39}$ & 0 & $b_{\geq 39}$ & 23.02 & $b_{\geq 39}$ & 0 & $b_{\geq 39}$ & 0 & $b_{\geq 39}$ & 0 & $b_{\geq 39}$ & 0 \\
\hline
\end{tabular}

\begin{tabular}{|c|c|c|c|c|c|c|c|c|c|c|c|c|c|c|c|c|c|c|c|}
\hline \multicolumn{2}{|c|}{$A_{11}$} & \multicolumn{2}{|c|}{$A_{12}$} & \multicolumn{2}{|c|}{$A_{13}$} & \multicolumn{2}{|c|}{$A_{14}$} & \multicolumn{2}{|c|}{$A_{15}$} & \multicolumn{2}{|c|}{$A_{16}$} & \multicolumn{2}{|c|}{$A_{17}$} & \multicolumn{2}{|c|}{$A_{18}$} & \multicolumn{2}{|c|}{$A_{19}$} & \multicolumn{2}{|c|}{$A_{20}$} \\
\hline$b_{\geq 35}$ & 0 & $b_{\geq 35}$ & 0 & $b_{\geq 35}$ & 11.99 & $b_{\geq 35}$ & 0.02 & $b_{\geq 35}$ & 81.42 & $b_{\geq 35}$ & 0 & $b_{\geq 35}$ & 41.16 & $b_{\geq 35}$ & 0.04 & $b_{\geq 35}$ & 71.57 & $b_{235}$ & 0.79 \\
\hline$b_{\geq 36}$ & 0 & $b_{\geq 36}$ & 0 & $b_{\geq 36}$ & 1.80 & $b_{\geq 36}$ & 0.01 & $b_{\geq 36}$ & 77.23 & $b_{\geq 36}$ & 0 & $b_{\geq 36}$ & 27.34 & $b_{\geq 36}$ & 0.015 & $b_{\geq 36}$ & 62.76 & $b_{\geq 36}$ & 0.11 \\
\hline$b_{\geq 37}$ & 0 & $b_{\geq 37}$ & 0 & $b_{\geq 37}$ & 0.46 & $b_{\geq 37}$ & 0.01 & $b_{\geq 37}$ & 69.80 & $b_{\geq 37}$ & 0 & $b_{\geq 37}$ & 5.05 & $b_{\geq 37}$ & 0 & $b_{\geq 37}$ & 49.14 & $b_{\geq 37}$ & 0.054 \\
\hline$b_{\geq 38}$ & 0 & $b_{\geq 38}$ & 0 & $b_{\geq 38}$ & 0.04 & $b_{\geq 38}$ & 0 & $b_{\geq 38}$ & 58.59 & $b_{\geq 38}$ & 0 & $b_{\geq 38}$ & 0.10 & $b_{\geq 38}$ & 0 & $b_{\geq 38}$ & 35.15 & $b_{\geq 38}$ & 0 \\
\hline$b_{\geq 39}$ & 0 & $b_{\geq 39}$ & 0 & $b_{\geq 39}$ & 0 & $b_{\geq 39}$ & 0 & $b_{\geq 39}$ & 26.65 & $b_{\geq 39}$ & 0 & $b_{\geq 39}$ & 0 & $b_{\geq 39}$ & 0 & $b_{\geq 39}$ & 23.73 & $b_{\geq 39}$ & 0 \\
\hline
\end{tabular}

\begin{tabular}{|c|c|c|c|c|c|c|c|c|c|c|c|c|c|c|c|c|c|c|c|}
\hline \multicolumn{2}{|c|}{$A_{21}$} & \multicolumn{2}{|c|}{$A_{22}$} & \multicolumn{2}{|c|}{$A_{23}$} & \multicolumn{2}{|c|}{$A_{24}$} & \multicolumn{2}{|c|}{$A_{25}$} & \multicolumn{2}{|c|}{$A_{26}$} & \multicolumn{2}{|c|}{$A_{27}$} & \multicolumn{2}{|c|}{$A_{28}$} & \multicolumn{2}{|c|}{$A_{29}$} & \multicolumn{2}{|c|}{$A_{30}$} \\
\hline$b_{\geq 35}$ & 1.22 & $b_{\geq 35}$ & 12.57 & $b_{235}$ & 82.63 & $b_{\geq 35}$ & 25.30 & $b_{\geq 35}$ & 8.24 & $b_{\geq 35}$ & 0.01 & $b_{\geq 35}$ & 0 & $b_{\geq 35}$ & 0 & $b_{\geq 35}$ & 0 & $b_{\geq 35}$ & 0 \\
\hline$b_{\geq 36}$ & 0.52 & $b_{\geq 36}$ & 8.77 & $b_{\geq 36}$ & 71.83 & $b_{\geq 36}$ & 15.29 & $b_{\geq 36}$ & 3.99 & $b_{\geq 36}$ & 0.01 & $b_{\geq 36}$ & 0 & $b_{\geq 36}$ & 0 & $b_{\geq 36}$ & 0 & $b_{\geq 36}$ & 0 \\
\hline$b_{\geq 37}$ & 0.31 & $b_{\geq 37}$ & 6.12 & $b_{237}$ & 66.85 & $b_{\geq 37}$ & 9.68 & $b_{\geq 37}$ & 0.51 & $b_{\geq 37}$ & 0 & $b_{\geq 37}$ & 0 & $b_{\geq 37}$ & 0 & $b_{\geq 37}$ & 0 & $b_{\geq 37}$ & 0 \\
\hline$b_{\geq 38}$ & 0.18 & $b_{\geq 38}$ & 3.27 & $b_{238}$ & 54.58 & $b_{\geq 38}$ & 1.58 & $b_{\geq 38}$ & 0.01 & $b_{\geq 38}$ & 0 & $b_{\geq 38}$ & 0 & $b_{\geq 38}$ & 0 & $b_{\geq 38}$ & 0 & $b_{\geq 38}$ & 0 \\
\hline$b_{\geq 39}$ & 0.07 & $b_{\geq 39}$ & 0.78 & $b_{\geq 39}$ & 24.81 & $b_{\geq 39}$ & 0.21 & $b_{\geq 39}$ & 0 & $b_{\geq 39}$ & 0 & $b_{\geq 39}$ & 0 & $b_{\geq 39}$ & 0 & $b_{\geq 39}$ & 0 & $b_{\geq 39}$ & 0 \\
\hline
\end{tabular}




\begin{tabular}{|c|c|c|c|c|c|c|c|c|c|c|c|c|c|c|c|c|c|}
\hline \multicolumn{2}{|c|}{$A_{31}$} & \multicolumn{2}{|c|}{$A_{32}$} & \multicolumn{2}{|c|}{$A_{33}$} & \multicolumn{2}{|c|}{$A_{34}$} & \multicolumn{2}{|c|}{$A_{35}$} & \multicolumn{2}{|c|}{$A_{36}$} & \multicolumn{2}{|c|}{$A_{37}$} & \multicolumn{2}{|c|}{$A_{38}$} & \multicolumn{2}{|c|}{$A_{39}$} \\
\hline$b_{\geq 35}$ & 0.62 & $b_{\geq 35}$ & 0 & $b_{\geq 35}$ & 0 & $b_{\geq 35}$ & 0 & $b_{\geq 35}$ & 0 & $b_{\geq 35}$ & 0 & $b_{\geq 35}$ & 0 & $b_{\geq 35}$ & 0 & $b_{\geq 35}$ & 0 \\
\hline$b_{\geq 36}$ & 0.14 & $b_{\geq 36}$ & 0 & $b_{\geq 36}$ & 0 & $b_{\geq 36}$ & 0 & $b_{\geq 36}$ & 0 & $b_{\geq 36}$ & 0 & $b_{\geq 36}$ & 0 & $b_{\geq 36}$ & 0 & $b_{\geq 36}$ & 0 \\
\hline$b_{\geq 37}$ & 0.03 & $b_{\geq 37}$ & 0 & $b_{\geq 37}$ & 0 & $b_{\geq 37}$ & 0 & $b_{\geq 37}$ & 0 & $b_{\geq 37}$ & 0 & $b_{\geq 37}$ & 0 & $b_{\geq 37}$ & 0 & $b_{\geq 37}$ & 0 \\
\hline$b_{\geq 38}$ & 0 & $b_{\geq 38}$ & 0 & $b_{\geq 38}$ & 0 & $b_{\geq 38}$ & 0 & $b_{\geq 38}$ & 0 & $b_{\geq 38}$ & 0 & $b_{\geq 38}$ & 0 & $b_{\geq 38}$ & 0 & $b_{\geq 38}$ & 0 \\
\hline$b_{\geq 39}$ & 0 & $b_{\geq 39}$ & 0 & $b_{\geq 39}$ & 0 & $b_{\geq 39}$ & 0 & $b_{\geq 39}$ & 0 & $b_{\geq 39}$ & 0 & $b_{\geq 39}$ & 0 & $b_{239}$ & 0 & $b_{\geq 39}$ & 0 \\
\hline
\end{tabular}




\section{Appendix B Necessary preference relation}

Table 15 Necessary preference relation obtained by applying the NAROR. For example, $A_{2}$ is necessarily preferred only to $A_{23}$

\begin{tabular}{|c|c|}
\hline Air_B $\left(\mathbf{A}_{2}\right)$ & $\mathrm{A}_{23}$ \\
\hline Bur_B (A5) & $A_{3}-A_{4}-A_{6}-A_{15}-A_{17}-A_{23}$ \\
\hline $\mathbf{C a v} \_\mathbf{A}\left(\mathbf{A}_{7}\right)$ & $\mathrm{A}_{21}$ \\
\hline Crc_A (A8) & $A_{2}-A_{3}-A_{4}-A_{6}-A_{15}-A_{17}-A_{23}-A_{35}-A_{36}-A_{37}$ \\
\hline Cum_A (A9) & $\mathrm{A}_{2}-\mathrm{A}_{23}-\mathrm{A}_{24}-\mathrm{A}_{25}$ \\
\hline Cum_B $\left(\mathbf{A}_{10}\right)$ & $\mathrm{A}_{6}-\mathrm{A}_{14}-\mathrm{A}_{21}-\mathrm{A}_{23}$ \\
\hline Frs_A $\left(\mathbf{A}_{11}\right)$ & $\begin{array}{l}A_{1}-A_{2}-A_{3}-A_{4}-A_{5}-A_{6}-A_{7}-A_{8}-A_{10}-A_{13}-A_{14}-A_{15}-A_{17}-A_{18}-A_{20}-A_{21}-A_{22}-A_{23}-A_{24}-A_{25}- \\
A_{31}-A_{35}-A_{36}-A_{37}-A_{38}\end{array}$ \\
\hline Frs_B $\left(\mathbf{A}_{12}\right)$ & $A_{1}-A_{2}-A_{3}-A_{4}-A_{5}-A_{6}-A_{7}-A_{10}-A_{13}-A_{14}-A_{15}-A_{17}-A_{21}-A_{23}-A_{24}-A_{25}-A_{35}-A_{36}-A_{37}$ \\
\hline Non_A $\left(\mathbf{A}_{14}\right)$ & $\mathrm{A}_{21}$ \\
\hline Pin_A $\left(\mathbf{A}_{16}\right)$ & $\mathrm{A}_{3}-\mathrm{A}_{13}-\mathrm{A}_{15}-\mathrm{A}_{17}-\mathrm{A}_{19}$ \\
\hline Pis_A (A18) & $\mathrm{A}_{23}$ \\
\hline Air_3 $\left(\mathbf{A}_{24}\right)$ & $\mathrm{A}_{25}$ \\
\hline Air_4 (A25) & $\mathrm{A}_{24}$ \\
\hline Non_1 (A26) & $\mathrm{A}_{14}-\mathrm{A}_{21}$ \\
\hline Fros_1 $\left(A_{27}\right)$ & $A_{2}-A_{3}-A_{6}-A_{13}-A_{15}-A_{17}-A_{19}-A_{23}$ \\
\hline Fros_2 (A 28$)$ & $A_{1}-A_{2}-A_{3}-A_{6}-A_{17}-A_{19}-A_{23}-A_{24}-A_{25}-A_{34}$ \\
\hline Pin_1 (A29) & $\mathrm{A}_{4}-\mathrm{A}_{15}$ \\
\hline Pin_2 $\left(\mathbf{A}_{30}\right)$ & $\mathrm{A}_{4}-\mathrm{A}_{15}-\mathrm{A}_{29}$ \\
\hline Pin_5 (A33) & $\mathrm{A}_{32}$ \\
\hline Rol_1 (A & $A_{1}-A_{2}-A_{3}-A_{6}-A_{17}-A_{19}-A_{23}-A_{24}-A_{25}$ \\
\hline Sca_1 (A & $\mathrm{A}_{37}$ \\
\hline Sca_2 (A & $\mathrm{A}_{35}-\mathrm{A}_{37}$ \\
\hline Sca_4 (A & $A_{2}-A_{3}-A_{4}-A_{5}-A_{6}-A_{8}-A_{15}-A_{17}-A_{20}-A_{22}-A_{23}-A_{31}-A_{35}-A_{36}-A_{37}$ \\
\hline Vol_2 (A39) & $\mathrm{A}_{22}$ \\
\hline
\end{tabular}




\section{References}

Angilella, S., Corrente, S., \& Greco, S. (2014). Stochastic Multiobjective Acceptability Analysis for the Choquet integral preference model and the scale construction problem.European Journal of Operational Research. In press, DOI: 10.1016/j.ejor.2014.06.031.

Angilella, S., Corrente, S., Greco, S., \& Słowiński, R. (2013). "Multiple Criteria HierarchyProcess for the Choquet Integral," in: Proceedings of EMO 2013, R.

Purshouse et al. (Eds.): EMO 2013. LNCS 7811, 475-489.

Angilella, S., Greco, S., Lamantia, F., \& Matarazzo, B. (2004). Assessing non-additive utility for multicriteria decision aid. European Journal of Operational Research, 158(3): 734-744.

Angilella, S., Greco, S., \& Matarazzo, B. (2010a). Non-additive robust ordinal regression: A multiple criteria decision model based on the Choquet integral. European Journal of Operational Research, 201(1), 277-288.

Angilella, S., Greco, S., \& Matarazzo, B. (2010b). The Most Representative Utility Function for Non-Additive Robust Ordinal Regression, in: Proceedings of IPMU 2010, E. Hullermeier, R. Kruse, and F. Hoffmann (Eds.): IPMU 2010, LNAI 6178, Springer, Heidelberg; 220-257.

ATO-R (Associazione d'Ambito Torinese per il Governo dei Rifiuti) (2007). Discarica per rifiuti non pericolosi del pinerolese. http://www.atorifiutitorinese.it/index.php?option=com_content\&task=view\&id=80\&Itemid=96.

Bobbio, L. (2011). Conflitti territoriali: sei interpretazioni. Tema, 4(4), 79-88

Bottero, M., Ferretti,V., \& Mondini, G. (2013). A Choquet integral - based approach for assessing the sustainability of a new waste incinerator. International Journal of Multicriteria Decision Making, 3(2/3), 157-177.

Brans, J.P., \& Vincke, Ph. (1985). A preference ranking organisation method: The PROMETHEE method for MCDM. Management Science, 31(6), 647-656.

Chateauneuf, A., \& Jaffray, J. Y. (1989). Some characterizations of lower probabilities and other monotone capacities through the use of Möbius inversion. Mathematical Social Sciences, 17, 263283.

Choquet, G. (1953). Theory of capacities. Annales Institute Fourier, 5(54),131-295. 
Corrente, S., Figueira, J.R., \& Greco, S. (2014a). Dealing with interaction between bipolar multiple criteria preferences in PROMETHEE method. Annals of Operations Research, 217(1), 137-164.

Corrente, S., Greco, S., \& Słowiński, R. (2012). Multiple Criteria Hierarchy Process in Robust Ordinal Regression. Decision Support Systems, 53(3), 660-674.

Corrente, S., Greco, S., \& Słowiński, R. (2013a). Multiple Criteria Hierarchy Process with ELECTRE and PROMETHEE. Omega, 41(5), 820-846.

Corrente, S., Greco, S., Kadziński, M., Słowiński, R. (2013b). Robust ordinal regression in preference learning and ranking. Machine Learning, 93 (2-3), 381-422.

Corrente, S., Greco, S., Kadziński, M., Słowiński, R. (2014b). Robust Ordinal Regression. Wiley Encycolpedia of Operations Research and Management Science. 1-10.

Dente, B. (2014). Understanding policy decisions, Berlin: Springer.

Ferretti, V., \& Pomarico, S. (2013). Ecological land suitability analysis through spatial indicators: An application of the Analytic Network Process technique and Ordered Weighted Average approach, Ecological Indicators, 34, 507-519.

Figueira, J.R., Greco, S., \& Ehrgott, M.(eds.) (2005). Multiple Criteria Decision Analysis: State of the Art Surveys. Berlin: Springer.

Figueira, J.R., Greco, S., \& Roy, B. (2009). ELECTRE methods with interaction between criteria: An extension of the concordance index. European Journal of Operational Research, 199, 478-495.

Figueira, J.R., Greco, S., \& Słowiński, R. (2010). Building a set of additive value functions representing a reference preorder and intensities of preference: GRIP method. European Journal of Operational Research, 195(2), 460-486.

Figueira, J.R., Greco, S., \& Słowiński, R. (2008). Identifying the "most representative" value function

among all compatible value functions in the GRIP. Proceedings of the $68^{\text {th }}$ EURO Working Group on MCDA, Chania, October 2008.

Foster, S.S.D. (1987). Fundamental concepts in aquifer vulnerability, pollution risk and protection strategy. In W. van, Duijvenbooden, \& H. G. van, Waegeningh (eds.). TNO Committee on Hydrological Research, The Hague. Vulnerability of soil and ground- water to pollutants, Proceedings and Information, 38,69-86. 
Giove, S., Rosato, P., \& Breil, M. (2011). An application of multicriteria decision making to built heritage. The redevelopment of Venice Arsenale. Journal of Multi-Criteria Decision Analysis, 17(34), 85-99.

Glasson, J., Therivel. R., Chadwick, A. (2013), Introduction to Environmental Impact Assessment, Routledge, London.

Grabisch, M. (1996). The application of fuzzy integrals in multicriteria decision making. European Journal of Operational Research, 89(3), 445-456.

Grabisch, M. (1997). k-order additive discrete fuzzy measures and their representation. Fuzzy Sets and Systems, 92,167-189.

Grabisch, M. \& Labreuche, C. (2010). A decade of application of the Choquet and Sugeno integrals in multi-criteria decision aid. Annals of Operations Research, 175(1): 247-286.

Grabisch, M., Kojadinovic, I., \& Meyer, P. (2008). A review of methods for capacity identification in Choquet integral based multi-attribute utility theory: Applications of the Kappalab R package. European Journal of Operational Research 186(2): 766-785.

Greco, S., Kadziński, M., Mousseau, V., \& Słowiński, R. (2011a). ELECTRE ${ }^{\text {GKMS }}$ : Robust ordinal regression for outranking methods. European Journal of Operational Research, 214(1), 118135.

Greco, S., Kadziński, M., Mousseau, V., \& Słowiński, R. (2012). Robust ordinal regression for multiple criteria group decision: UTA $^{\text {GMS }}$-GROUP and UTADIS ${ }^{\text {GMS }}$-GROUP. Decision Support Systems, 52, 549-561.

Greco, S., Kadziński, M., \& Słowiński R. (2011b). Selection of a representative value function in robust multiple criteria sorting. Computers \& Operations Research, 38:1620-1637.

Greco, S., Matarazzo, B., \& Słowiński R. (2001). Rough sets theory for multicriteria decision analysis. European Journal of Operational Research, 129(1), 1-47.

Greco, S., Mousseau, V., \& Słowiński R. (2008). Ordinal regression revisited: multiple criteria ranking using a set of additive value functions. European Journal of Operational Research, 191(2):416-436.

Greco, S., Mousseau, V., \& Słowiński, R. (2014). Robust ordinal regression for value functions handling interacting criteria. European Journal of Operational Research. In Press. DOI: 10.1016/j.ejor.2014.05.022 
Kadziński, M., Greco, S., \& Słowiński, R. (2011). Selection of a representative value function in robust multiple criteria ranking and choice. European Journal of Operational Research, 217(3),541553.

Kadziński, M., Greco, S., \& Słowiński, R. (2012a). Extreme ranking analysis in robust ordinal regression. Omega, 40(4), 488-501.

Kadziński, M., Greco, S., \& Słowiński, R. (2012b). Selection of a representative set of parameters for robust ordinal regression outranking methods. Computers \& Operations Research, 39(11), 25002519.

Kadziński, M., Greco, S., \& Słowiński, R. (2013). Selection of a representative value function for robust ordinal regression in group decision making. Group Decision and Negotiation,

22(3), 429-462.

Kadziński, M., \& Tervonen, T. (2013). Robust multi-criteria ranking with additive value models and holistic pair-wise preference statements. European Journal of Operational Research, 228 (1), 169-180.

Keeney, R.L., \& Raiffa, H. (1993). Decisions with multiple objectives: Preferences and value tradeoffs. New York: J. Wiley.

Lahdelma, R., Hokkanen, J., \& Salminen, P. (1998). SMAA-Stochastic multiobjective acceptability analysis. European Journal of Operational Research, 106, 137-143.

Malczewski, J. (1999). GIS and Multicriteria Decision Analysis. New York: John Wiley and Sons.

Marichal, J.L., \& Roubens, M. (2000). Determination of weights of interacting criteria from a reference set. European Journal of Operational Research 124(3): 641-650.

Mousseau, V., Figueira, J.R., Dias, L., Gomes da Silva, C., \& Climaco, J. (2003). Resolving inconsistencies among constraints on the parameters of an MCDA model. European Journal of Operational Research, 147(1), 72-93.

Munda, G. (2005). Social multi-criteria evaluation for urban sustainability policies. Land Use Policy, 23 (1), 86-94.

Murofushi, S., \& Soneda, T. (1993). Techniques for reading fuzzy measures (III): interaction index. $9^{\text {th }}$ Fuzzy Systems Symposium, Sapporo, Japan, pp. 693-696.

Rosenhead, J., Mingers, J. (Eds.) (2001) Rational analysis for a problematic word Revised. Wiley, Chichester 
Rota, G.C. (1964). On the foundations of combinatorial theory I. Theory of Möbius functions. Wahrscheinlichkeitstheorie und Verwandte Gebiete, 2, 340-368.

Roy, B., \& Bouyssou, D. (1993). Aide multicritère à la décision: méthodes et cas. Paris: Economica.

Roy, B, Słowiński, R. (2013) Questions guiding the choice of a multicriteria decision aiding method. EURO Journal on Decision Process 1: 69-97

Singh, R.S., Murty, H.R., Gupta, S.K., Dikshit, A.K. (2012). An overview of sustainability assessment methodologies, Ecologial Indicators, 15, 281-299.

Shafer, G. (1976). A Mathematical Theory of Evidence. Princeton: Princeton University Press.

Shapley, L.S. (1953). A value for n-person games. In A. W., Tucker, \& H. W., Kuhn (eds.), Contributions to the Theory of Games II, p. 307. Princeton: Princeton University Press.

Tervonen, T., \& Figueira, J.R. (2008). A survey on stochastic multicriteria acceptability analysis methods. Journal of Multi-Criteria Decision Analysis, 15(1-2):1-14.

Wakker, P.P. (1989). Additive representations of preferences: A new foundation of decision analysis. Kluwer Academic Publishers. 